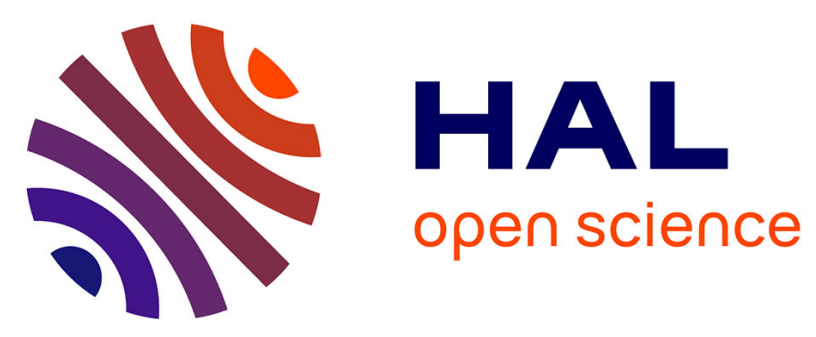

\title{
Disentangling the roles of bottom-up and top-down drivers in the trade-off between food acquisition and safety in prey with multiple predators
}

Olivier Pays, Pierrick Blanchard, Simon Chamaillé-Jammes, Marion Valeix, Andrew J Loveridge, David W Macdonald, Stéphanie Périquet, Esther van Der Meer, Patrick Duncan, Godfrey Mtare, et al.

\section{To cite this version:}

Olivier Pays, Pierrick Blanchard, Simon Chamaillé-Jammes, Marion Valeix, Andrew J Loveridge, et al.. Disentangling the roles of bottom-up and top-down drivers in the trade-off between food acquisition and safety in prey with multiple predators. Functional Ecology, 2020, 10.1111/1365-2435.13710 . hal-03029443

\section{HAL Id: hal-03029443 https://hal.science/hal-03029443}

Submitted on 28 Nov 2020

HAL is a multi-disciplinary open access archive for the deposit and dissemination of scientific research documents, whether they are published or not. The documents may come from teaching and research institutions in France or abroad, or from public or private research centers.
L'archive ouverte pluridisciplinaire HAL, est destinée au dépôt et à la diffusion de documents scientifiques de niveau recherche, publiés ou non, émanant des établissements d'enseignement et de recherche français ou étrangers, des laboratoires publics ou privés. 


\section{Disentangling the roles of bottom-up and top-down drivers in the trade-off between food acquisition and safety in prey with multiple predators}

Olivier Pays ${ }^{*}, a, k, 1$, Pierrick Blanchard ${ }^{b}$, Simon Chamaillé-Jammes ${ }^{c, d, k}$, Marion Valeix $^{e, f, k}$, Andrew J Loveridge ${ }^{f}$, David W Macdonald ${ }^{f}$, Stéphanie Périquet ${ }^{e}$, Esther van der Meer ${ }^{\mathrm{g}}$, Patrick Duncan ${ }^{\mathrm{h}, \mathrm{k}}$, Godfrey Mtare ${ }^{\mathrm{i}}$, Hervé Fritz ${ }^{\mathrm{e}, \mathrm{j}, \mathrm{k}, \mathrm{l}}$

a LETG-Angers, UMR 6554 CNRS, Université d'Angers, Campus Belle Beille, 2 Bd Lavoisier, 49045 Angers, France.

${ }^{\text {b }}$ Laboratoire Evolution et Diversité Biologique, UMR 5174 CNRS, ENSFEA, Université Paul Sabatier Toulouse III, Toulouse, France

${ }^{C}$ CEFE, Univ. Montpellier, CNRS, EPHE, IRD, Université Paul Valéry Montpellier 3, Montpellier, France

${ }^{\mathrm{d}}$ Mammal Research Institute, Department of Zoology \& Entomology, University of Pretoria, Pretoria, South Africa

e CNRS, Université Lyon, Université Lyon 1, Laboratoire de Biométrie et Biologie Evolutive UMR 5558, F-69622 Villeurbanne, France.

${ }^{f}$ Wildlife Conservation Research Unit (WildCRU), Zoology Department, Oxford University, RecanatiKaplan Centre, Tubney House, Abingdon, OX13 5QL, United Kingdom.

${ }^{g}$ Painted Dog Conservation, Hwange National Park, P.O.Box 72, Dete, Zimbabwe. 
${ }^{\text {h }}$ Centre d'Etudes Biologiques de Chizé, UMR 7372 CNRS-Université de la Rochelle, Beauvoir-surNiort, France

' Parks and Wildlife Management Authority, P.O. Box CY 140, Causeway, Harare, Zimbabwe

${ }^{\mathrm{j}}$ Sustainability Research Unit, Nelson Mandela University, George Campus, Madiba Drive, 6531 George, South Africa

${ }^{\mathrm{k}}$ LTSER France, Zone Atelier CNRS Hwange, Hwange National Park, Bag 62, Dete, Zimbabwe

'REHABS International Research Laboratory, CNRS-Université Lyon 1-Nelson Mandela University, George Campus, Madiba drive 6531 George, South Africa.

${ }^{*}$ Corresponding author: Olivier Pays, LETG-Angers, UMR 6554 CNRS, Université d'Angers, Campus Belle Beille, 2 Bd Lavoisier, 49045 Angers, France. e-mail address: olivier.pays@univ-angers.fr (O. Pays), phone: +33 (0) 241735261.

\section{Acknowledgements}

This work was funded by the CNRS INEE ("Institut Ecologie et Environnement"); the "Zones Ateliers" network LTSER France; the Agence Nationale de la Recherche (FEAR project ANR-08-BLAN-0022); the CIRAD; the French "Ministère des Affaires Etrangères" and the "Ambassade de France au Zimbabwe". The Director General of the Zimbabwe Parks and Wildlife Management Authority is acknowledged for providing the opportunity to carry out this research: we are particularly grateful to $\mathrm{Dr}$. $\mathrm{H}$. Madzikanda for his long term support and friendship and our warm thanks also go to Mr. A. Musakwa, the then Area Manager, for his support. This study is part of the HERD program (Hwange Environmental Research Development), now Hwange LTSER (Zone Atelier Hwange): we would like to thank the whole HERD team including Martin Muzamba, Marion Lombard, Tawanda Tarakini, Gugulethu Ncube, Stéphane Sourice and François-René Favreau for their insight in the fertilisation 
experiment and video sequences. Finally, we thank Jane Hunt, Brent Stapelkamp and Nicholas Elliot for their insight on collecting data in lions and Matt Hayward and two anonymous referees of their helpful comments.

\section{Authors' contributions}

OP, PB, SCJ, MV, PD and HF conceived the ideas and designed methodology;

$\mathrm{OP}, \mathrm{PB}, \mathrm{HF}$ lead the creation of plots and collected data on vegetation;

$\mathrm{OP}, \mathrm{PB}, \mathrm{SP}$ collected data on impalas;

AJL, DWM, SP, EVM collected data on carnivores;

$\mathrm{OP}, \mathrm{HF}$ analysed the data;

OP led the writing of the manuscript.

All authors have improved the manuscript with significant comments

\section{data availability statement.}

Data are available on doi:10.5061/dryad.b5mkkwhbq (Pays et al. 2020) 


\title{
Disentangling the roles of bottom-up and top-down drivers in the
}

\section{trade-off between food acquisition and safety in prey with multiple}

\author{
predators
}

\section{Abstract}

1. Prey face a trade-off between acquiring food and avoiding predation, but food availability, and therefore its effect, is rarely measured in field studies investigating non-lethal effects of predation. The main aim of this study is to investigate the role of the presence of predators in the functional adjustments of feeding parameters with patch quality in a medium-size herbivore.

2. In Hwange National Park (Zimbabwe), we set up an experiment by manipulating, over two years, patch quality for impala (Aepyceros melampus), a medium-sized herbivore. We assess predation risk by monitoring the presence of three GPS-equipped predators: African lions (Panthera leo), spotted hyaenas (Crocuta crocuta) and African wild dogs (Lycaon pictus).

3. In enriched, fertilised plots the impalas reduced step rates (i.e. the rates of change in feeding stations), and increased their number of bites per feeding station while bite rates were not affected. Thus, the main adjustment of their feeding was the step rate. The total time the impalas spent vigilant appeared to be a good predictor of the variation of their bite rate. Although vigilance caused a reduction in bite rate when at a feeding station, the impalas reduced the relative costs of vigilance by continuing chewing and processing their food when scanning for predators. 
4. When predators were in the vicinity, the impalas increased their exclusive vigilance (high-cost vigilance) but not their vigilance while chewing (low-cost vigilance) and decreased their bite rate while their step rate and the number of bites per feeding station did not change significantly. The impalas were thus visually disconnected from their patch, and reduced their bite rate when actually foraging. Exclusive vigilance increased when both lions and hyaenas were in the vicinity, and when wild dogs were nearby.

5. Patterns of vigilance that altered bite rate were linked to the presence of predators during the previous $24 \mathrm{~h}$. Over the long term patch quality was the main determinant of the feeding parameters (step rate and bite rate). This study shows how predators, by affecting the time prey devote to predator detection, shape the functional adjustments of food acquisition by prey to local patch quality.

\section{Key-words}

Antipredator response; Feeding rate; Foraging strategy; Herbivore; Patch quality; Risk effect; Savanna; Vigilance 


\section{Introduction}

Limitation of populations under natural conditions is driven by both bottom-up and top-down drivers (Sinclair et al. 2000; Shurin et al. 2002; Hayward, O’Brien \& Kerley 2007; Hopcraft, Olff \& Sinclair 2010). Food abundance and quality have been reported to control herbivore biomass (Fritz \& Duncan 1994) as they affect the physical condition of individuals and thus their capacity to survive and breed (Mduma, Sinclair \& Hilborn 1999). The role of predators in the limitation of prey populations through numerical lethal effects (e.g. direct killing) has been demonstrated in numerous studies (Sinclair, Mduma \& Brashares 2003; Preisser, Bolnick \& Bernard 2005; Heithaus et al. 2009). In addition, antipredator behaviours of prey, such as changes in habitat use (e.g. Werner et al. 1983), changes in temporal niches (Valeix et al. 2009a), vigilance (e.g. Dröge et al. 2017) and foraging strategies (e.g. Barnier et al. 2014), may have energetic (e.g. Kotler, Brown \& Bouskila 2004) and physiological consequences (e.g. stress, Boonstra et al. 1998; Creel, Winnie \& Christianson 2009), which can adversely affect prey demography (e.g. Lima 1998; Creel \& Christianson 2008; Zanette et al. 2011). Although the antipredator responses of prey have been well described (Creel 2018), assessments of the costs of these responses are scarce and little is known about the non-lethal effects of the presence of predators on large mammalian prey populations (Creel et al. 2017, Say-Sallaz et al. 2019)

Vigilance is one behaviour that is central to the trade-off between food acquisition and safety, and contributes to the indirect impact of predators on the fitness of prey through its link with fitness-enhancing activities (Hopcraft, Olff \& Sinclair 2010). Although maintaining high levels of predator detection allows prey to reduce their probability of being killed, this strategy is likely to reduce food acquisition and thus to incur fitness costs (Brown \& Kotler 2004). Studies in birds (Fritz, Guillemain \& Durant 2002) and mammals (Fortin et al. 2004) have reported that an increase of vigilance significantly reduced feeding efficiency (e.g. instantaneous intake rate) of foragers. This 
trade-off between foraging costs and vigilance may be critical when food resources are of poor nutritional quality, forcing foragers to maximise their foraging effort.

In studies investigating the non-lethal effects of the presence of predators, information on the spatial and temporal variation in food availability for prey is often lacking, particularly in studies of vigilance strategies in free-ranging animals. This makes it difficult or impossible to disentangle the roles played by predation pressure and food quality in shaping the trade-off between food acquisition and predator detection (McNamara \& Houston 1994). When food biomass and quality are not measured, it is uncertain whether vigilance behaviour of prey reduces food intake rate up to the point where it jeopardizes fitness, as intake rates vary with patch quality and biomass (Cromsigt \& Olff 2006; Owen-Smith, Fryxell \& Merrill 2010). Although the foraging strategies of herbivores have been well studied (Spalinger \& Hobbs 1992; Wilmshurst, Fryxell \& Colucci 1999), the impacts of variations in forage characteristics, particularly when they are seasonally driven, on the foraging costs of vigilance are far from clear (Favreau et al. 2018). For instance, studies of short-grass grazers have shown that higher grass biomasses are generally less digestible (Fryxell 1991), making the relationship between food intake and the greenness and biomass of food (i.e. two proxies of patch quality) complex to understand. However, an increase in vigilance is likely to affect food acquisition differently if the animals are foraging in patches of different forage characteristics and quality: food acquisition is affected by grass height and density (through their effects on bite sizes and rates), and the chemical composition of grass affects its digestibility. Moreover, during antipredator vigilance, many animals, including birds (Baker et al. 2011) and mammals (Blanchard \& Fritz 2007), reduce foraging costs by exhibiting vigilance while processing food (e.g. chewing) or moving (Illius \& Fitzgibbon 1994; Fortin et al. 2004). Vigilance with chewing contrasts with high-cost vigilance (called exclusive vigilance) during which individuals stop handling food. Thus, the effects of predation risk on food acquisition should be examined with attention to the way these two types of vigilance affect 
functional adjustments in foraging parameters that influence intake rates (particularly bite rate and step rate) in relation to patch quality.

Variations in prey animals' perception of predation risk (such as high vs low risk habitats) affects the time prey allocate to foraging (Winnie \& Creel 2007) and food acquisition (Sansom, Lind \& Cresswell 2009). Although some studies have investigated responses of prey to a single predator species (Chamaillé-Jammes et al. 2014; LaManna \& Martin 2016), we know little about the effects of the presence of more than one predator species on vigilance strategies and consequently on food intake rates. Most natural ecological systems are multi-predator systems in which prey can be caught by several predator species (Sinclair, Mduma \& Brashares 2003, Thaker et al. 2011, Creel et al. 2017, Montgomery et al. 2019). For a complete understanding of the trade-off between vigilance and food acquisition in these multi-predator systems, it is important to determine how prey alter their intake rate in response to specific predator species and the presence of single versus multiple predator species. Finally, it is uncertain for how long after a predator is near the prey, it affects the trade-off between food acquisition and predator detection by prey particularly when they do not encounter their predators every day (Middleton et al. 2013, Courbin et al. 2016).

To examine the role of predators and food quality in shaping the trade-off between food acquisition and predator detection, we studied vigilance and foraging strategies in impala (Aepyceros melampus), a medium-sized herbivore, in Hwange National Park (HNP), Zimbabwe. Over a two-year period, we used an experiment in which patch quality was manipulated by fertilising and mowing plots in a grassland (cutting stimulates regrowth, Leriche et al. 2003), thus affecting both plant biomass and its quality (the proportion of green plant material). Predation risk was investigated by monitoring the presence of three predators, African lions (Panthera leo), spotted hyaenas (Crocuta crocuta) and African wild dogs (Lycaon pictus) marked with GPS-collars.

We first assessed how impalas adjusted their feeding behaviour to patch quality (biomass and greenness) controlling for the presence of predators and perceived predation risk (visibility 
around the individual impalas). Three parameters were used to describe impala feeding behaviour: bite rate, i.e. the number of bites per min, step rate, i.e. the number of steps per min, and the ratio between the number of bites and steps (the number of bites per feeding station), which is an indicator of the number of bites per feeding station. Bite rate can be a proxy of intake rate, as it is highly dependent on the rate of bite encounters, i.e. bite density, and on bite size, since bigger bites take longer to chew hence lowering bite rate. In our study, grass biomass was mostly below $50 \mathrm{~g} / \mathrm{m}^{2}$ (see FigS1 Appendix1). Below this value, medium sized antelopes and gazelles are limited in their adjustment of bite size (Wilmshurst, Fryxell \& Colucci 1999; Wilmshurst, Fryxell \& Bergman 2000). Thus, bite size can vary but not in relation to patch biomass. Hence, we expected feeding parameters in impalas foraging in our study area to respond more to the proportion of green tissues than variation of grass biomass. This limited possibility to adjust bite size implies that bite rate was a reasonable proxy of intake rate, and this intake rate was more dependent on encounter rate than chewing rate (Process 2 of Spalinger \& Hobbs 1992). Step rate while foraging gives an index of the rate of change in feeding stations, with a greater rate of change when grass quality is low. While step rate may affect the bite rates and the local density of acceptable bites, step rate can be influenced by disturbance mechanisms unrelated to food. Thus, one metric that may directly translate the perception of feeding patches giving a better description of the perceived patch quality is the ratio bite rate/step rate (the number of bites per feeding station). If the amount of acceptable bites in a given patch is high, the number of bites per feeding station is high. Thus we predicted that under low predation risk, step rate should decrease with increases in patch quality while bite rate remains stable, resulting in an increase in the number of bites per feeding station with patch quality i.e. in enriched patches of tall grass (Fig 1a).

We tested the effects of perceived predation risk (measured by the level of vigilance) and the recent nearby occurrence of predators on the feeding behaviour of impalas (bite rate) and how impalas perceived and used feeding patches (indicated by the number of bites per feeding station). 
We expected to find one or both of two patterns of adjustment to perceived predation risk (Pattern 1.1 and 1.2) and one pattern to the recent nearby occurrence of predators (Pattern 2) which are presented in the Figure 1. Pattern 1.1 and 1.2 result from perceived predation risk that increases the need for low-cost vigilance (while chewing or moving) and causes adjustment of step rate or bite rate, respectively. In Pattern 1.1 the animal maintains selectivity for high quality bites. When the cropping process is interrupted by vigilance before the mouth is full, the individual leaves the partially depleted patch to go to a better patch with higher densities of acceptable bites, thus increasing step rate. It is also consistent with vigilance interruption impairing searching for food items in a partially depleted patch (Fritz et al. 2002). This would lead to a decrease in the number of bites per feeding station mostly induced by higher step rate (Fig $1 \mathrm{~b}$ ). In Pattern 1.2, the animal broadens the acceptability of bites in a given patch to achieve a full mouth before vigilance interrupts it. This implies more bites per patch and smaller distances between bites, therefore higher bite rates, leading to an increase of the number of bites per feeding station because of this increase of bite rate for a given feeding station (Fig. 1c).

When predators are actually present, the level of vigilance should be higher for both low and high-cost vigilance (Favreau et al. 2013). We expected a different pattern (Pattern 2) in which the increase of high-cost vigilance visually disconnected the individual from its food patch, inducing a greater cost of searching for acceptable bites. Under this scenario, we expected the number of bites per feeding station to decrease because bite rate decreases (Fig 1d), particularly in the tall grass where searching may be more difficult, but mainly because visibility while foraging with head down is poor and thus perceived as risky (Pays et al. 2012). If the costs of resuming searching for remaining bites is high, then stepping to another feeding station would be an alternative option allowing for vigilance while moving. As in Pattern 1, this would cause an increase in step rate.

Previous observations in HNP reported that zebras, Equus quagga, encountered lions at night every 35 days on average (Courbin et al. 2016). Thus observations with predators in the vicinity of 
impalas may be rare compared to the ones without predators. From a statistical standpoint, this may lead to failure to detect an effect of the recent nearby occurrence of collared predators on the behaviours of the impalas. To avoid missing an effect of predation on the trade-off between food acquisition and vigilance, we compared vigilance and bite rates and step rates of focal impalas on days when collared predators had been in the vicinity during the previous 24 hours with observations on days before their arrival (i.e. the preceding 24 hours). We also investigated whether behavioural adjustments were more extreme when more than one predator species was present.

\section{Materials and methods}

Study site

Hwange National Park (HNP) hosts an exceptional diversity of mammals including most of the small to large herbivores and carnivores observed in Southern African savannas (Fritz et al. 2011). The fieldwork was conducted near Main Camp in the north of HNP $\left(19^{\circ} 00^{\prime} \mathrm{S}, 26^{\circ} 30^{\prime} \mathrm{E}\right)$. The study site is an open grassland area of 64 ha surrounded by Acacia and Combretum bushes, typical of the mixed bushed grassland on nutrient-poor soils of the eastern Kalahari sands. Bushes form a natural and visually obstructive boundary of the grassland. The long-term mean annual rainfall is $600 \mathrm{~mm}$ and the rainy season occurs between October and April (Chamaillé-Jammes, Fritz \& Murindagomo 2006). The fieldwork was conducted from January to August in 2009 and 2010, which received $823.6 \mathrm{~mm}$ and $935.4 \mathrm{~mm}$ of rainfall respectively.

The density $( \pm \mathrm{SD})$ of impalas around Main Camp was $1.43 \mathrm{impalas} / \mathrm{km}^{2}( \pm 0.63)$ (ChamailléJammes et al. 2009). Impalas are expected to be top-down limited (Hopcraft, Olff \& Sinclair 2010) as their body mass averages $45 \mathrm{~kg}$ (Cumming \& Cumming 2003), i.e. below the 180-200kg threshold under which population dynamics of prey should be controlled by predation (Sinclair, Mduma \& Brashares 2003). Impalas are preferred by African wild dogs, cheetahs (Acynonyx jubatus), and 
leopards (Panthera pardus) (Hayward \& Kerley 2008) and other large carnivores such as spotted hyaenas and lions also feed on impalas (e.g. impalas represent $17 \%$ and $8 \%$ of the total number of prey found in lion and hyaena scats respectively in HNP (Davidson et al. 2013 and Périquet et al. 2015 respectively)). Impalas are mixed feeders and their feeding strategy varies seasonally (Jarman 1974): they are predominantly grazers while grasses are green and growing, and browsers of foliage, forbs, shoots and seedpods at other times. Here, we studied behavioural responses of impalas when they were grazing. Focals when impalas browsed short bushes or trees were excluded from this analysis.

From 50 to 150 impalas (mainly adult females and juveniles) foraged each day at the study site. All adult females in the study site formed a single herd (as described in Jarman \& Jarman 1973) which divided into a variable number of groups with marked fusion-fission dynamics. It was not possible to capture and mark all individuals in the study population. However, since the year 2000 newborn fawns have been captured and tagged on an annual basis, it was possible to regularly observe about 30 ear-tagged adult females. Ear-tagged individuals allowed us to confirm that individuals randomly selected for observations (called 'focals' here) were rarely resampled and the effect of potential pseudo-replication is therefore negligible.

\section{Ethical Statement}

The experiments complied with the laws (including animal welfare ethics) of Zimbabwe. They were approved and conducted under permits from the Director General of the Zimbabwe Parks and Wildlife Management Authority (Ref: DM/Gen/ (T), Permit numbers: 23(I) (c) (ii): 01/2009 and 01/2010 for the impala behavioural study and hyaena collaring, 03/2009 and 25/2010 for lion collaring, and 09/2009 and 07/2010 for wild dog collaring). The long-term individual-based study on impala population dynamics in HNP started in 2000 under permits from the same authorities cited above. 


\section{Experimental design}

We manipulated the impalas' food resources by spreading common fertiliser for pasture $(\mathrm{N}: 3.5 \%$, $\mathrm{P}_{2} \mathrm{O}_{5}, 24.4 \%$, S: $11.0 \%$ and $\mathrm{Zn}: 0.5 \%$, at $70 \mathrm{~kg} / \mathrm{ha}$ ) and by mowing (cutting) grass to increase both the biomass and the proportion of grass that was green (and thus high quality) since herbivores select for green tissues (e.g. Murray \& Baird 2008). Four enriched and four control plots $(60 \times 120 \mathrm{~m})$, all including strips of cut and uncut grass, were created at different distances from cover (Fig 2). Fertilisation and mowing were performed in January 2009 and 2010, two weeks before the beginning of the behavioural studies. We confirmed that fertilisation and mowing changed grass availability and quality by measuring grass biomass, greenness and bare soil in all plots (192 samples in 2009 and 353 in 2010 for the three cited variables). Grass biomass was measured using a previously calibrated diskpasture meter and the proportion of green tissues and the average grass cover were estimated visually by using photographs (as in Vanha-Majamaa et al. 2000, see Pays et al. 2012 for details, and see Appendix 1 for statistical details and variations among seasons and between years and the effects on patch quality). On average, during the 2-year experiment, biomass was $30 \%$ higher in enriched plots compared to control plots in uncut strips while we did not detect any significant difference in cut strips. The proportion of green tissues was $25 \%$ higher in enriched plots than in control plots in cut strips and $13 \%$ higher in uncut strips. In cut and uncut strips, the proportion of bare soil was on average $17 \%$ lower in enriched plots compared to control plots.

\section{Recording behaviour}

We studied vigilance and foraging behaviours of impalas by videotaping focal adult females only (hence avoiding adding sex-age effects), for 5 -min periods chosen at random during the daytime from February to August. Juveniles were present in all groups; it was not possible to say at which 
female each juvenile belonged to. We filmed individuals in groups whose predominant activity during the video sequence was grazing. 5-min focals were sufficient to obtain sequences during which both foraging and vigilance behaviours could be studied. In total we recorded 740 sequences: 532 in 2009 and 208 in 2010.

Observations were made from vehicles, maintaining a minimum distance of $100 \mathrm{~m}$ between the focal group and the observer to minimize disturbance. When several individuals were filmed during the same day, the observer took care to avoid filming the same individuals to ensure independence between observations. Finally, it was crucial that animals did not move long distances (i.e. stayed in the same ecological conditions) during the 5-min video sequences to ensure that food biomass and quality remained approximately stable during the focal. So we rejected focals during which the individual left the plot and did not forage in the same mowed or uncut strips during the 5 min video sequence. We sampled 163 impalas foraging inside enriched plots, 58 in control plots and 519 outside plots (Fig 2c). We considered data collected outside plots as uncut controls.

An impala was considered vigilant when it raised its head above the horizontal, scanning its surroundings, without moving its feet. Previous studies have shown that impala often chew when vigilant, but it is assumed that this multitasking might reduce their ability to hear approaching predators. Impalas have indeed been observed to stop chewing when hearing a threatening stimulus (Blanchard \& Fritz 2007; Favreau et al. 2013). Thus, we extracted the total time an individual spent in vigilance, distinguishing high-cost vigilance when impalas stopped chewing their bites while vigilant and low-cost vigilance when they continued chewing. From each focal, we also recorded when individuals moved their left front leg to calculate the step rate and when they took a bite (easily recognizable by jerky head movements) to calculate the bite rate. We then calculated the number of bites per feeding station.

The observer recorded date, time of day and the location of the focal females on a field map. Visibility around foraging individuals was categorized based on the height of the grass (Grass height), 
which was visually estimated and classified in four classes: short when grass height was not above the focal impala's hooves distinguishing between cut (short cut) and uncut (short uncut) strips, medium when it was below the upper part of the impala's metacarpals, and high when it reached the impala's tibia. In tall grass, how easily the focal impala could see the potential predators was assumed to be strongly limited. The position of the individuals within a group (i.e. peripheral or central) was impossible to determine during the video sampling because the animals moved constantly when foraging. Although distance to cover was assessed through three classes: $\leq 50,50-$ 100 , and $>100 \mathrm{~m}$, we did not detect any effect of this variable on any of the vigilance and foraging behaviours of impalas (Chi-square tests, all $\mathrm{P}>0.54$ ), probably because we included plot identity as a random factor and plots were set up at different distances to cover. Moreover, although group size was assessed during video sampling, we did not detect any effect of the log-transformed group size, considering the two way interactions on any feeding parameters (Chi-square tests, all $P>0.080$ ) and vigilance activities (Chi-square tests, all $\mathrm{P}>0.071$ ), probably because the range of group size was not great enough since we avoided small group sizes (the mean group size $( \pm S D)=41.74 \pm 32.70$, range from 10 to 108 individuals). Thus, we did not consider these two variables in the final analyses.

\section{Carnivore data}

Long-term GPS-tracking studies of large carnivores in HNP allowed us to investigate how the presence of carnivores influenced impala foraging behaviour. During the study period, 7 lions in different groups $(2$ female adults from 2 different prides and 5 male adults from 5 different coalitions), 5 spotted hyaenas distributed in 2 clans, and 2 wild dogs representative of 2 clans of 5 and 7 individuals were tracked around the study site, which they did use. Given the size of the different predator groups, this leads to the following proportions of collared individuals for the local populations of lions, wild dogs and hyaenas respectively: $0.50,0.20$, and 0.17 . Collared individuals visited the study site in 2009 and 2010 occasionally or regularly. We assumed that these individuals 
were representative of the movements of their groups at least for lions (Valeix et al. 2009b) and wild dogs (van der Meer 2011) (see Appendix 2 for more details). Although other predator species were not collared, visits of cheetah and leopard were rarely observed during the study. We therefore assumed that predation pressure at the study site was mainly driven by the three monitored predator species. Because lions and hyaenas are active mainly at night and move little during the day, GPS locations were acquired every hour from $18 \mathrm{~h}$ to $6 \mathrm{~h}$ hours, plus two fixes during the day. For wild dogs, GPS locations were acquired every 100 minutes day and night (see van der Meer 2011; Benhamou et al. 2014; Périquet et al. 2015 for details on captures and GPS-collars of wild dogs, lions and hyaenas respectively). From GPS coordinates of collared predators, we determined whether predators occurred in the vicinity of the focal impalas (i.e. within a radius of $2 \mathrm{~km}$ centred around the focal impala) in the 24 hours preceding the focal. A previous study in the same area reported that vigilance of prey including impala was affected by predators at this $2 \mathrm{~km}$ threshold (Périquet et al. 2012). Predators were present within $2 \mathrm{~km}$ of the focal impalas in 127 of the 740 video sequences, including 97 sequences with lion only, 19 with wild dog only and 11 with both lion and hyaena. As we observed only hyaenas only once, and the combination wild dog with lions only once, we discarded these two sequences for the analyses.

\section{Data analysis}

\section{Functional adjustment of foraging}

We fitted linear mixed effect models to test for the effect of food quality or quantity on the variations in bite rate. We included plot enrichment (whether the impala foraged on control or enriched plots), grass height (contrasting the four classes, i.e. high, medium, short uncut, short cut), predator within $2 \mathrm{~km}$ (whether GPS-collared predators were present in the 2 surrounding $\mathrm{km}$ in the preceding 24 hours, i.e. no or yes) and two two-way interactions as independent variables: 
$w(x)=\beta_{0}+\beta_{1}($ Plot enrichment $)+\beta_{2}($ Predator within $2 \mathrm{~km})+\beta_{3}($ Grass height $)+\beta_{4}($ Plot enrichment $x$ Predator within $2 \mathrm{~km})+\beta_{5}($ Predator within $2 \mathrm{~km} \times$ Grass height $)(1)$

With $w(x)$, the response variable (e.g. bite rate), $\beta_{0}$, the intercept and $\beta_{k}$ the coefficient estimated for each predictor $x_{k}$. Because of the mowing of the grass, the two-way interaction Plot enrichment $x$ Grass height could not be considered in the models. We included year (contrasting 2009 and 2010), season (contrasting three periods i.e. Feb.-March, April-May or July-Aug.) and plot identity as nested random factors to control for time and spatial correlations that might occur in the data set. To capture the sequential structure of the data set, we converted the dates of focals to Julian days cumulated over the two years and applied an autocorrelation function of order 1 using the function corAR1. We tested the effect of each variable using likelihood ratio tests (i.e. $\left.\chi^{2}\right)$. We used post-hoc Tukey tests for multiple comparisons when necessary. The same procedure was applied to the logtransformed step rate and the number of bites per feeding station. We paid special attention to check the normality of residuals, the distribution of residuals against fitted values and the lack of sequential autocorrelation in residuals (see Appendix 4).

Trade-offs between bite rate, the number of bites per feeding station and vigilant behaviour

To investigate how investment in vigilance affected bite rate in these impalas, we fitted linear mixedeffect models including total time in vigilance as the predictor and bite rate as the dependent variable. We log-transformed the total time spent in vigilance to achieve statistical requirements on model's residuals:

$w(x)=\beta_{0}+\beta_{1}(\log ($ Total vigilance $))$

With $w(x)$, the response variable (e.g. bite rate), $\beta_{0}$, the intercept and $\beta_{1}$, the coefficient derived for the predictor. Year, season and plot identity were included as nested random factors and an autocorrelation function of order 1 on Julian day as described earlier. The same procedure was used 
to test the effect of vigilance on the number of bites per feeding station and the effect of low and high-cost vigilance on bite rate and the number of bites per feeding station.

Effect of the presence of collared predators in the surroundings

Although Eq. 1 allowed us to examine whether predator presence affected foraging and vigilance over the whole period, we ran the same model (Eq. 1) comparing focals when collared predators were in the surroundings in the $24 \mathrm{~h}$ preceding the focals $(\mathrm{N}=127)$ with focals the day before their arrivals $(\mathrm{N}=69)$. We used linear mixed-effect models including year and season as nested random factors. To compare focals belonging to the same event, we created a variable called predator event identity allowing focals during which a collared predator was present to be linked to focals collected the day before their arrival and included it as a random factor nested into year and season. We applied the same autocorrelation function of order 1 on the Julian day as described earlier. We tested the effect of each variable using likelihood ratio tests (i.e. $\chi^{2}$ ). The residuals of the model were analysed and they fulfilled statistical requirements (see Appendix 4). The same procedure was applied on bite rate, the log-transformed step rate and the number of bites per feeding station.

Finally, we tested for differences in vigilance including high and low-cost vigilance (logtransformed), bite rate, the log-transformed step rate and the number of bites per feeding station between different categories of predation risk within the surrounding $2 \mathrm{~km}$ (lion only, wild dog only vs lion with hyaena) using linear mixed effects models including predator species within $2 \mathrm{~km}$ and grass height and including year, season and predator event identity as nested random factors:

$w(x)=\beta_{0}+\beta_{1}($ Predator species within $2 \mathrm{~km})+\beta_{3}($ Grass height $)$

With $w(x)$ as bite rate, the log-transformed step rate and number of bites per feeding station, $\beta_{0}$, the intercept and $\beta_{\mathrm{k}}$ the coefficient derived for each predictor $\mathrm{x}_{\mathrm{k}}$. The size of the data set did not allow us to test for the effect of two-way interactions with each type of collared predator on foraging 
parameters and vigilance, as each type of predator was not observed in each class of grass height. We applied the same autocorrelation function of order 1 on the Julian day as described earlier. The residuals of the model were analysed and they fulfilled statistical requirements.

Statistical analyses were performed using R 3.6.2 (R Development Core Team 2019). Models were performed with the nlme package (Pinheiro et al. 2019) and multiple comparisons with the Ismeans package (Lenth 2016).

\section{Results}

Functional adjustments of foraging parameters

On average, bite rate, step rate and the number of bites per feeding station (mean \pm SD) in impalas foraging in our study area were $30 \pm 9.60,4.5 \pm 3.60$, and $15 \pm 20$ respectively. Plot enrichment and grass height affected certain foraging parameters of these impalas. As expected, bite rate declined in taller grass ( $22 \%$ reduction between tall and short cut grass, Fig. $3 a)$, with the highest values when impalas foraged in short cut strips (Table 1). We did not detect any significant effect of plot enrichment on bite rate (Table 1), but step rate was lower by $27 \%$ and the number of bites per feeding station higher by $18 \%$ in enriched than in control plots (Fig. $3 b, d$ ). On average, step rate declined in the tall grass by $12 \%$ (Table 1, Fig. 3c) although we did not detect any difference between medium and short- grass height for step rate (Appendix 3 for multiple comparisons). Contrary to step rate, the number of bites per feeding station increased in tall grass by $53 \%$ (Table 1, Fig. 3e) with no difference between medium and short grass height (Appendix 3). To conclude, when plot enrichment increased patch quality (see Appendix 1), impalas reduced their step rate by 1 step per minute on average and gained 3 bites per feeding station. 
Trade-offs between bite rate, the number of bites per feeding station and vigilance

The impalas spent on average ( \pm SD) $15 \%( \pm 13)$ of their foraging time in vigilance with $22 \%( \pm 20)$ of their total vigilance spent in high-cost vigilance. Thus, while vigilant, individuals mostly continue chewing and processing their food. Bite rate decreased with the log-transformed time spent in vigilance $\left(\beta \pm S E=-11.213 \pm 0.611, \chi^{2}=273.044, d f=1, P<0.001\right.$, pseudo $\left.R^{2}=0.35\right)$, high-cost vigilance $\left(\beta \pm S E=-3.450 \pm 0.289, \chi^{2}=131.586, d f=1, P<0.001\right.$, pseudo $\left.R^{2}=0.16\right)$ and low-cost vigilance $\left(\beta \pm S E=-6.788 \pm 0.631, \chi^{2}=100.988, d f=1, P<0.001\right.$, pseudo $\left.R^{2}=0.18\right)$. Figure 4 shows that when individuals invested a lot in vigilance to detect predators (for instance $66 \%$ of their foraging time, i.e. $\log (2.4))$, impalas could lose up to 20 bites per minute, falling from 40 to 20 .

The number of bites per feeding station also decreased with the log-transformed time spent in vigilance $\left(\beta \pm S E=-0.134 \pm 0.033, \chi^{2}=16.045, d f=1, P=0.001\right.$, pseudo $\left.R^{2}=0.01\right)$ and high-cost vigilance $\left(\beta \pm S E=-3.450 \pm 0.289, \chi^{2}=42.007, d f=1, P<0.001\right.$, pseudo $\left.R^{2}=0.05\right)$ whereas low-cost vigilance had no effect $\left(\chi^{2}=0.725, d f=1, P=0.394\right)$. Despite the significant patterns, the pseudo $\mathrm{R}^{2}$ were low and the investment in vigilance was not a good predictor of the number of bites per feeding station.

Effect of the presence of collared predators in the surroundings

Collared predators were present in the surroundings (within $2 \mathrm{~km}$ ) during 18 days of the 114 days of data collection. Contrasting focals during these 18 days with the ones from the day before the predator's arrival (controls) and controlling for the effects of grass height, showed that the presence of collared predators (regardless of species) affected bite rate but did not affect step rate or the number of bites per feeding station (Table 2). On average, impalas lost about 4 bites per minute when predators were in the surroundings ( $14 \%$ reduction) with no difference of bite rate between a single predator species or multi-predator species $\left(\chi^{2}=1.999, d f=2, P=0.368\right)$. Finally, the presence 
of collared predators affected both the total time spent in vigilance and high-cost vigilance (Table 3) but did not affect low-cost vigilance $\left(\chi^{2}=1.986, d f=2, P=0.370\right)$. Compared to days before the predator's arrival (controls), impalas were more vigilant and increased their high-cost vigilance when wild dogs were in surroundings by $101 \%$ and $167 \%$ respectively and when both lions and hyaenas were present by $116 \%$ and $355 \%$ respectively although we did not detect any significant difference when only lions were present (Table 4, Fig. 5).

\section{Discussion}

Functional adjustment of foraging parameters

As reported in other species of herbivores including warthog (Phacochoerus aethiopicus) and white rhinoceros (Ceratotherium simum) (Cromsigt \& Olff 2006), our study shows that local patch quality shapes the feeding strategy of impalas. In enriched plots, impalas reduced their step rate, the rate of change in feeding stations, and increased their number of bites per feeding station while bite rate was not affected. The main adjustment parameter for the intake rate is therefore step rate. By adjusting step rate to maintain bite rate, hence presumably intake rate, impala decreased the number of bites per feeding station in control plots (for enrichment, Fig. 3d) i.e. in places where there was a smaller proportions of green material. This analysis of feeding parameters from the experimental plots suggests that intake rate is limited by the encounter rate of acceptable bites, as occurs in the Process 2 in the theoretical framework of Spalinger and Hobbs (1992). This result is consistent with both our prediction of the selective feeding strategy in such medium-sized ruminants (see Fig. 1a) and other studies in the same species (Fritz \& de Garine-Wichatitsky 1996). Our results suggest that for medium-sized and large herbivores that use step rate as an adjusting parameter of intake rate, individuals may 
use low-cost vigilance (i.e. vigilance while chewing or moving) to minimise cost of predator detection (Blanchard \& Fritz 2007).

Grass height commonly shapes feeding parameters (e.g. bite size), and hence food intake rate in grazing herbivores (Arsenault \& Owen-Smith 2008). Our results show that in tall grass bite rate and step rate were low and the number of bites per feeding station was high indicating that the amount of acceptable bites was high in patches of tall grass. For a selective herbivore like impala, the difficulty in finding high quality green blades in tall grass may lead individuals to reduce their speed when they forage in tall patches when predators are absent. However, as visibility around them is low, individuals may also reduce speed as the perception of predation risk is high, investing more in vigilance (Pays et al. 2012). Thus more studies are needed to clarify the functional adjustments with grass height in the trade-off between feeding and detection of predators.

To improve patch quality, besides fertilization, we mowed grass to stimulate regrowth and thus increase the availability of green leaves. Our results show that bite rate, step rate and the number of bites per feeding station did not change significantly between short mown and naturally short grasses. The impalas responded clearly to fertilisation particularly when they foraged in tall grass. However, the effect of mowing on their feeding behaviour was not significant. Indeed, although the percentage of green material was higher in cut strips, the difference in biomass between cut (mown) and uncut strips was small, particularly in 2010, even in fertilised plots (Appendix 1) and might have therefore limited the opportunity to detect an effect of mowing on foraging.

Trade-offs between bite rate, the number of bites per feeding station and vigilance Both high and low-cost vigilance have been examined here, and the total time spent in vigilance was the best predictor of the variation in bite rate. Vigilance altered bite rate (and 
potentially intake rates) as reported in previous studies (Fortin et al. 2004), although it had no effect on the number of bites per feeding station. When at a feeding station, impalas reduced the relative costs of vigilance by continuing chewing and processing their food (Pays et al. 2012). Our results show that impalas spent around $80 \%$ of their vigilance time in low-cost vigilance, indicating how individuals can considerably reduce the potential costs of predator detection when they are foraging.

Feeding with larger bites could mitigate foraging costs of vigilance in grazing herbivores (see Spalinger \& Hobbs 1992, and Wilmshurst et al 1999 for an example in gazelles). Larger bites would induce longer chewing bouts, increase spare time and allow individuals to use low-cost vigilance for longer periods. However, in our study, grass biomass was mostly below the optimal value for impala (see Introduction) and it is unlikely that patch biomasses on this site allowed individuals to take larger bite sizes. Our results suggest that step rate was the adjusting parameter of intake rate, so we expect impalas to increase their step rate between two feeding stations to improve bite quality (i.e. to detect patches with more green tissues) and to increase encounter rates (Spalinger \& Hobbs 1992). Finally, although we did not detect a group-size effect on foraging and vigilance activities (as we mostly sampled individuals in large groups), it has been commonly reported in gregarious species (Jarman 1974), including impalas (Pays et al. 2012), that individuals forage in large groups to reduce foraging costs of vigilance and reallocate the time for predator detection to foraging (FitzGibbon 1989, 1990).

Effects of the presence of predators and perceived predation risk Creel et al. (2014) analysed the variation of antipredator behaviours and their foraging costs in five ungulates (zebra, Equus quagga, Grant's gazelle, Nanger granti, wildebeest, Connochaetes taurinus, impala and giraffe, Giraffa camelopardalis) in response to the 
presence of lions and spotted hyaenas in the surroundings. They found that the increase of vigilance in response to the presence of predators triggered a large reduction in time spent foraging in four species including impala but not in wildebeest. In our study, we show that in response to the presence of collared predators, impalas 1) were more vigilant, increasing their exclusive (i.e. high-cost) vigilance and 2) on average they reduced bite rate while maintaining their step rate and the number of bites per feeding station. These results suggest that the presence of predators leads individuals to use more vigilance, which visually disconnects foragers from their food and leads to lower bite rates (Fig. 1d). Thus our results may apply to other herbivore prey species in which an increase in vigilance is likely to affect food acquisition. This is particularly expected in tall grass where both bite rate and visibility are low for individuals foraging head down. However, in tall grass bite rate and step rate were low while the number of bites per feeding station was high, our results therefore fully support the expected Pattern 2 as the decrease in bite rate did not lead to a decrease of the number of bites per feeding station when predation risk was high. Finally, our results did not support the hypothesis under which perceived predation risk would increase the need for low-cost vigilance hence reduce the number of bites per feeding station (Pattern 1.1, Fig 1b) or broaden the acceptability of bites in a given patch, leading to an increase of the number of bites per feeding station (particularly in short grass) (Pattern 1.2, Fig 1c).

Several studies have reported that prey exhibit a large range of proactive behavioural strategies including adjustment of space use, group size and time spent in risky habitat to decrease overall predation risk and to invest in fitness-enhancing activities such as foraging (Valeix et al. 2009b, Basille et al. 2015, Courbin et al. 2019). The interaction between vigilance and proactive space use is complex and might make applying predictions to other systems difficult (Patin et al. 2019). In addition, other studies have shown that prey can reactively adjust their space use (Middleton et al. 2013, Courbin et al. 2016) or increase their 
time allocated to vigilance in response to cues of predation risk (Pays et al. 2013, Dannock et al. 2018), as was the case when impalas were stimulated by lion roars (Favreau et al. 2013) or faeces of wild dogs (van der Meer, Fritz \& Pays 2015). We show here that impalas increased their vigilance by increasing their high-cost vigilance when two predators (i.e. lion with hyaena) or when wild dogs were in the surroundings. Although our data on hyaenas did not allow us to examine focals with only hyaenas in the surroundings, our results show that the largest increase of high-cost vigilance in impalas was observed when two predators (lions and hyaenas) were present at the same time in the surroundings. As the increase of vigilance with lions only in the surroundings was small, we might expect that the presence of hyaenas affected the vigilance of impalas. Overall, our results suggest that although impala is the main prey of African wild dogs (Hayward \& Kerley 2008, van der Meer et al. 2014), the presence of two predators at the same time may be perceived as the most important threat. Although our data did not allow us to investigate finer time and spatial scales (due to sample size constraints), it would be very interesting to test for behavioural adjustments to predation risk at other time lags.

Analyses over the whole study show that patch quality is the main determinant of feeding parameters (step rate and bite rate). However, these impalas do respond to predators in their vicinity by increasing their vigilance, and this reduced bite rate. This effect was clear only when we compared focal samples from the 24 hour periods when predators were nearby with focals from the days before. Although our experimental design focused on a large herd of impalas (up to 150 individuals) foraging in one grassland area where many predators were collared, some individual impalas may have been affected by uncollared predators. Our study highlights the need to conduct fine scale analyses in order to understand the effect of patch quality and predators on the trade-off between food acquisition and predator detection. In this context, an important aspect of understanding the effect of the predators on feeding 
parameters and ultimately the foraging costs of vigilance in prey is the frequency of encounters of the prey with the predator. We suggest that this time scale issue merits specific attention in future studies.

\section{References}

Arsenault R., Owen-Smith N. 2008. Resource partitioning by grass height among grazing ungulates does not follow body size relation. Oikos 117: 1711-1717

Baker D. J., Stillman R. A., Smart S. L., Bullock J. M., Norris, K. J. 2011. Are the costs of routine vigilance avoided by granivorous foragers? Functional Ecology 25:617-627

Basille M., Fortin D., Dussault C., Bastille-Rousseau G., Ouellet J. P, Courtois R. 2015. Plastic response of fearful prey to the spatio-temporal dynamics of predator distribution. Ecology 96:2622-2631

Barnier F., Valeix M., Duncan P., Chamaillé-Jammes S., Barre P., Loveridge A. J., Macdonald D. W., Fritz H. 2014. Diet quality in a wild grazer declines under the threat of an ambush predator. Proceedings of the Royal Society B 281:20140446

Benhamou S., Valeix M., Chamaillé-Jammes S., Macdonald D. W., Loveridge A. J. 2014. Movement-based analysis of interactions in African lions. Animal Behaviour 90:171-180

Blanchard P., Fritz H. 2007. Induced or routine vigilance while foraging. Oikos 116:16031608

Boonstra R., Hik D., Singleton G. R., Tinnikov A. 1998. The impact of predator induced stress on the snowshoe hare cycle. Ecological Monographs 68:371-394

Brown J. S., Kotler B. P. 2004. Hazardous duty pay and the foraging cost of predation. Ecology Letters 7:999-1014

Chamaille- Jammes S., Fritz H., Murindagomo F. 2006. Spatial patterns of the NDVI-rainfall relationship at the seasonal and interannual time scales in an African savanna. International Journal of Remote Sensing 27:5185-5200

Chamaillé-Jammes S., Valeix M., Bourgarel M., Murindagomo F., Fritz H. 2009. Seasonal density estimates of common large herbivores in Hwange National Park, Zimbabwe. African Journal of Ecology 44:804-808. 
Chamaillé-Jammes S., Malcuit H., Le Saout S., Martin J. L. 2014. Innate threat-sensitive foraging: black-tailed deer remain more fearful of wolf than of the less dangerous black bear even after 100 years of wolf absence. Oecologia, 174, 1151-1158.

Courbin N., Loveridge A. J., Macdonald D. W., Fritz H., Valeix M., Makuwe E. T., Chamaillé-Jammes, S. 2016. Reactive responses of zebras to lion encounters shape their predator-prey space game at large scale. Oikos 125:829-838

Courbin N., Loveridge A. J., Fritz H., Macdonald D. W., Patin R., Valeix M., Chamaillé- Jammes S. 2019. Zebra diel migrations reduce encounter risk with lions at night. Journal of Animal Ecology 88:92-101

Creel S. 2018. The control of risk hypothesis: reactive vs. proactive antipredator responses and stress-mediated vs. food-mediated costs of response. Ecology Letters 21: 947-956

Creel S., Christianson D. 2008. Relationships between direct predation and risk effects. Trends in Ecology \& Evolution 23:194-201

Creel S., Dröge E., M'soka J., Smit D., Becker M., Christianson D., Schuette P. 2017. The relationship between direct predation and antipredator responses: a test with multiple predators and multiple prey. Ecology 98:2081-2092

Creel S., Schuette P., Christianson D. 2014. Effects of predation risk on group size, vigilance and foraging behavior in an African ungulate community. Behavioral Ecology 25:773784

Creel S., Winnie J. A., Christianson D. 2009. Glucocorticoid stress hormones and the effect of predation risk on elk reproduction. Proceedings of the National Academy of Sciences 106:12388-12393

Cromsigt J. P. G. M., Olff H., 2006. Resource partitioning among savanna grazers mediated by local heterogeneity: an experimental approach. Ecology 87:1532-1541

Cumming D. H. M., Cumming G. S. 2003. Ungulate community structure and ecological processes: body size, hoof area and trampling in African savannas. Oecologia 134:560568

Dannock R., Pays O., Renaud P. C., Maron M., Goldizen A. 2019. Assessing blue wildebeests' vigilance, grouping and foraging responses to perceived predation risk using playback experiments. Behavioral Processes 164:252-259

Davidson Z., Valeix M., van Kesteren F., Loveridge A. J., Hunt J. E., Murindagomo F. \& Macdonald D. W. 2013. Seasonal diet and prey preference of the African lion in a waterhole-driven semi-arid savanna. PLoS ONE 8: e55182. 
Dröge E., Creel S., Becker M., M'soka J. 2017. Risky times and risky places interact to affect prey behaviour. Nature Ecology \& Evolution 1:1123-1128

Favreau F. R., Goldizen A. W., Fritz H., Pays O. 2018. Food supply fluctuations constrain group sizes of kangaroos and in turn shape their vigilance and feeding strategies. Animal Behaviour 135: 165-176

Favreau F. R., Pays O., Goldizen A. W., Fritz H. 2013. Short-term behavioural responses of impalas in simulated antipredator and social contexts. PLoS ONE 8:e84970

FitzGibbon C. D. 1989. Cost to individuals with reduced vigilance in groups of Thomson's Gazelles hunted by cheetahs. Animal Behaviour 37:508-510

FitzGibbon C. D. 1990. Why do hunting cheetahs prefer male gazelles? Animal Behaviour 40:837-845

Fortin D., Boyce M. S., Merrill E. H., Fryxell J. M. 2004. Foraging costs of vigilance in large mammalian herbivores. Oikos 107:172-180

Fritz H., de Garine-Wichatitsky M. 1996. Foraging in a social antelope: effects of group size on foraging choices and resource perception in impala. Journal of Animal Ecology 65:736-742.

Fritz H., Duncan P. 1994. On the carrying capacity for large ungulates of African savanna ecosystems. Proceedings of the Royal Society B 256: 77-82.

Fritz H., Guillemain M., Durant D. 2002. The cost of vigilance for intake rate in the mallard (Anas platyrhynchos): An approach through foraging experiments. Ethology Ecology \& Evolution 14: 91-97

Fritz H., Loreau M., Chamaillé-Jammes S., Valeix M., Clobert J. 2011. A food web perspective on large herbivore community limitation. Ecography 34:196-202

Fryxell J. M. 1991. Forage quality and aggregation by large herbivores. The American Naturalist 138: 478-498

Hayward M. W., O'Brien J., Kerley G. I. H. 2007. Carrying capacity of large African predators: predictions and tests. Biological Conservation 139: 219-229

Hayward M. W., Kerley G. I. H. 2008. Prey preferences and dietary overlap amongst Africa's large predators. South African Journal of Wildlife Research 38:93-108

Heithaus M. R., Wirsing A. J., Burkholder D., Thomson J., Dill L. M. 2009. Towards a predictive framework for predator risk effects: the interaction of landscape features and prey escape tactics. Journal of Animal Ecology 78:556-562 
Hopcraft G. C., Olff H., Sinclair A.R.E. 2010. Herbivores, resources and risks: alternating regulation along primary environmental gradients in savannas. Trends in Ecology and Evolution 25:119-128

Illius A. W., FitzGibbon C. 1994. Costs of vigilance in foraging ungulates. Animal Behaviour $47: 481-484$

Jarman P. J. 1974. The social organisation of antelope in relation to their ecology. Behaviour $48: 215-267$

Jarman M. V., Jarman P. J. 1973. Daily activity of impala. African Journal of Ecology 11:7592

Kother B. P., Brown J. S., Bouskila A. 2004. Apprehension and time allocation in gerbils: the effects of predatory risk and energetic state. Ecology 85:917-922

LaManna J. A., Martin T. E. 2016. Costs of fear: behavioural and life-history responses to risk and their demographic consequences vary across species. Ecology Letters 19:403-413

Lenth R. V. 2016. Least-Squares Means: The R Package lsmeans. Journal of Statistical Software, 69:1-33

Leriche H., Le Roux X., Desnoyers F., Benest D., Abbadie L. 2003. Grass response to clipping in an African savanna: Testing the grazing optimisation hypothesis. Ecological Applications 13:1346-1354

Lima S. L. 1998. Nonlethal Effects in the Ecology of Predator-Prey Interactions: What are the ecological effects of anti-predator decision-making? Bioscience 78: 25-34

McNamara J. M., Houston A. I. 1994. The effect of a change in foraging options on intake rate and predation rate. The American Naturalist 144: 978-1000

Middleton A. D., Kauffman M. J., McWhirter D. E., Jimenez M. D., Cook R. C., Cook J. G., Albeke S. E., Sawyer H., White P. J. 2013. Linking anti-predator behaviour to prey demography reveals limited risk effects of an actively hunting large carnivore. Ecology Letters 16:1023-1030.

Mduma S. A. R., Sinclair A. R. E., Hilborn R. 1999. Food regulates the Serengeti wildebeest: a 40-year record. Journal of Animal Ecology 68:1101-1122

Montgomerya R. A., Molla R. J., Say-Sallaz E., Valeix M., Prughe L. R. 2019. A tendency to simplify complex systems. Biological Conservation 233, 1-11

Murray M. G., Baird D. R. 2008. Resource-ratio theory applied to large herbivores. Ecology 89:1445-1456 
Owen-Smith N., Fryxell J. M., Merrill E. H. 2010. Foraging theory upscaled: the behavioural ecology of herbivore movement. Philosophical Transactions of the Royal Society B $365: 2267-2278$

Patin R., Fortin D., Sueur C., Chamaillé-Jammes S. 2019. Space Use and Leadership Modify Dilution Effects on Optimal Vigilance under Food-Safety Trade-Offs. The American Naturalist 193:E15-E28

Pays O., Beauchamp G., Carter A. J., Goldizen A. W. 2013. Foraging in groups allows collective predator detection in a mammal species without alarm calls. Behavioral Ecology 24:1229-1236

Pays O., Blanchard P., Valeix M., Chamaillé-Jammes S., Duncan P., Périquet S., Lombard M., Ncube G., Tarakini T., Makuwe E., Fritz H. 2012. Detecting predators and locating competitors while foraging: an experimental study of a medium-sized herbivore in an African savanna. Oecologia 169:419-430

Pays O., Blanchard P., Chamaillé-Jammes S., Valeix M., Loveridge A.J., Macdonald D.W., Périquet S., Van der Meer E., Duncan P., Mtare G., Fritz H. 2020. Disentangling the roles of bottom-up and top-down drivers in the trade-off between food acquisition and safety in prey with multiple predators. Dryad, Dataset, https://doi.org/10.5061/dryad.b5mkkwhbq

Périquet S., Todd-Jones L., Valeix M., Stapelkamp B., Elliot N., Wijers M., Pays O., Fortin D., Madzikanda H., Fritz H., Macdonald D. W., Loveridge A. J. 2012. Influence of immediate predation risk by lions on the vigilance of prey of different body size. Behavioral Ecology 23:970-976

Périquet S., Valeix M., Claypole J., Drouet- Hoguet N., Salnicki J., Mudimba S., Revilla E., Fritz H. 2015. Spotted hyaenas switch their foraging strategy as a response to changes in intraguild interactions with lions. Journal of Zoology 297:245-254

Pinheiro J., Bates D., DebRoy S., Sarkar D., R Core Team. 2019. nlme: Linear and Nonlinear Mixed Effects Models. R package version 3.1

Preisser E. L., Bolnick D. I., Bernard, M. F. 2005. Scared to death? The effects of intimidation and consumption in predator- prey interactions. Ecology 86:501- 509

R Development Core Team. 2019. R: a language and environment for statistical computing. R Foundation for Statistical Computing, Vienna

Sansom A., Lind J., Cresswell W. 2009. Individual behavior and survival: the roles of predator avoidance, foraging success, and vigilance. Behavioral Ecology 20: 1168-1174 
Say-Sallaz E., Chamaillé-Jammes S., Fritz H., Valeix M. 2019. Non-consumptive effects of predation in large terrestrial mammals: mapping our knowledge and revealing the tip of the iceberg. Biological Conservation 235:36-52

Shurin J. B., Borer E. T., Seabloom E. W., Anderson K., Blanchette C. A., Broitman B., Cooper S. D., Halpern B. S. 2002. A cross-ecosystem comparison of the strength of trophic cascades. Ecology Letters 5:785-791

Sinclair A. R. E., Krebs C. J., Fryxell J. M., Turkington R., Boutin S., Boonstra R., Seccombe-Hett P., Lundberg P., Oksanen L. 2000. Testing hypotheses of trophic level interactions: A boreal forest ecosystem. Oikos 89:313-328

Sinclair A. R. E., Mduma S. A. R., Brashares, J. S. 2003. Patterns of Predation in a Diverse Predator-Prey System. Nature 425:288-90

Spalinger D. E., Hobbs N. T. 1992. Mechanisms of foraging in mammalian herbivores: new models of functional response. American Naturalist 140:325-348

Thaker M., Vanak A. T., Owen C. R., Ogden M. B., Niemann S. M., Slotow R. 2011. Minimising predation risk in a landscape of multiple predators: effects on the spatial distribution of African ungulates. Ecology 92:398-407

Valeix M., Fritz H., Loveridge A.J., Davidson Z., Hunt J.E., Murindagomo F., Macdonald D.W. 2009a. Does the risk of encountering lions influence African herbivore behaviour at waterholes? Behavioral Ecology and Sociobiology 63: 1483-1494.

Valeix M., Loveridge A. J., Chamaillé-Jammes S., Davidson Z., Murindagomo F., Fritz H., Macdonald D. W. 2009b. Behavioral adjustments of African herbivores to predation risk by lions: Spatiotemporal variations influence habitat use. Ecology 90:23-30 van der Meer E. 2011. Is the grass greener on the other side? Testing the ecological trap hypothesis for African wild dogs (Lycaon pictus) in and around Hwange National Park. Doctoral thesis. University of Lyon 1, France

van der Meer E., Fritz H., Blinston P., Rasmussen, G. S. A. 2014. Ecological trap in the buffer zone of a protected area: effects of indirect anthropogenic mortality on the African wild dog Lycaon pictus. Oryx 48:285-293

van der Meer E., Fritz H., Pays O. 2015. Anti predator behaviour of kudu and impala in response to mimicked African wild dogs presence: do age and sex matter? Behaviour, 152:1209-1228 
Vanha-Majamaa I., Salemaa M., Tuominen S., Mikkola K. 2000. Digitized photographs in vegetation analysis-a comparison of cover estimates. Applied Vegetation Science 3:8994

Werner E. E., Gilliam J. F., Hall D. J., Mittelbach G. G. 1983. An experimental test of the effects of predation risk on habitat use in fish. Ecology 64:1540-1548

Wilmshurst J. F., Fryxell J. M., Colucci P. E. 1999. What constrains daily intake in Thomson's gazelles? Ecology 80:2338-2347

Wilmshurst J. F., Fryxell J. M., Bergman C. M. 2000. The allometry of patch selection in ruminants. Proceedings of the Royal Society B 267:345-349

Winnie J., Creel S. 2007. Sex-specific behavioural responses of elk to spatial and temporal variation in the threat of wolf predation. Animal Behaviour 73:215-225

Zanette L. Y., White A. F., Allen M. C., Clinchy M. 2011. Perceived predation risk reduces the number of offspring songbirds produce per year. Science 334:1398-1401 
Table 1. Factors influencing the bite rate (bite per minute), step rate (step per minute, logtransformed) and number of bite per step (Log-transformed) of impalas over the 2-year period $\beta \pm \mathrm{SE}$ are indicated for significant variables. Plot enrichment indicated whether the impala foraged on control or enriched plots, Predator within $2 \mathrm{~km}$ indicated whether GPS collared predators were present within $2 \mathrm{~km}$ (no and yes), grass height contrasted 4 classes (High, medium, short, short cut) and Log Group Size was the log-transformed group size in which the focal impala was studied with classes in italics that were considered as references in the linear mixed-effects model including Year, Season and Plot ID as nested random factors.

\begin{tabular}{|c|c|c|c|c|c|}
\hline $\begin{array}{l}\text { Dependant } \\
\text { Variables }\end{array}$ & Predictors & $\chi^{2}$ & Df & $P$ & $\beta \pm S E(P)$ \\
\hline \multirow{8}{*}{ Bite rate } & & & & & (intercept: $30.944 \pm 1.392$ ) \\
\hline & Plot enrichment & 0.023 & 1 & 0.878 & \\
\hline & Predator within $2 \mathrm{~km}$ & $\begin{array}{l}1.190 \\
8\end{array}$ & 1 & 0.167 & \\
\hline & & & & & Medium: $1.461 \pm 0.789$ (0.065) \\
\hline & Grass height & 14.10 & 3 & 0.003 & Short: $4.060 \pm 1.409$ (0.005) \\
\hline & & & & & Short cut: $3.073 \pm 1.327(\mathbf{0 . 0 2 1})$ \\
\hline & Plot enrichment $\times$ Predator within $2 \mathrm{~km}$ & 1.025 & 1 & 0.599 & \\
\hline & Predator within $2 \mathrm{~km} \times$ Grass height & 6.079 & 3 & 0.108 & \\
\hline \multirow{8}{*}{ Log (Step rate) } & & & & & (intercept: $0.429 \pm 0.061$ ) \\
\hline & Plot enrichment & 2.709 & 1 & 0.033 & Enriched plot: $-0.080 \pm 0.035$ \\
\hline & Predator within $2 \mathrm{~km}$ & 0.003 & 1 & 0.957 & \\
\hline & & 23.52 & & & Medium: $0.104 \pm 0.032$ (0.001) \\
\hline & Grass height & & 3 & $<0.001$ & Short: $0.195 \pm 0.054(<0.001)$ \\
\hline & & & & & Short cut: $0.186 \pm 0.053(<0.001)$ \\
\hline & Plot enrichment $\times$ Predator within $2 \mathrm{~km}$ & 3.732 & 1 & 0.155 & \\
\hline & Predator within $2 \mathrm{~km} \times$ Grass height & 5.170 & 3 & 0.160 & \\
\hline \multirow{8}{*}{$\begin{array}{l}\text { Log (Bites per } \\
\text { feeding station) }\end{array}$} & & & & & (intercept: $1.028 \pm 0.053$ ) \\
\hline & Plot enrichment & 4.234 & 1 & 0.039 & Enriched: $0.128 \pm 0.054$ \\
\hline & Predator within $2 \mathrm{~km}$ & 0.279 & 1 & 0.598 & \\
\hline & & 12.77 & & & Medium: $-0.117 \pm 0.037(\mathbf{0 . 0 0 2})$ \\
\hline & Grass height & 6 & 3 & 0.005 & Short: $-0.116 \pm 0.062(0.060)$ \\
\hline & & & & & Short cut: $-0.147 \pm 0.058$ (0.013) \\
\hline & Plot enrichment $\times$ Predator within $2 \mathrm{~km}$ & 5.119 & 1 & 0.078 & \\
\hline & Predator within $2 \mathrm{~km} \times$ Grass height & 6.346 & 3 & 0.096 & \\
\hline
\end{tabular}


Table 2. Factors influencing the bite rate (bites per minute, BR), step rate (steps per minute, log-transformed, SR) and number of bites per step (log-transformed, B/S) of impalas when comparing the behaviour of focals when GPS collared predators were present and the day before the arrival of the predators. $\beta \pm \mathrm{SE}$ are indicated for significant variables. Plot enrichment indicates whether the impala foraged on control or enriched plots, predator within $2 \mathrm{~km}$ indicates whether GPS collared predators were present within $2 \mathrm{~km}$ of the impalas (no and yes), grass height contrasts 4 classes (High, medium, short, short cut) and Log Group size is the log-transformed group size in which the focal impala was studied with classes in italics that were considered as references in the linear mixed-effects model including Year, Season and Predator event ID as nested random factors.

\begin{tabular}{|c|c|c|c|c|c|}
\hline $\begin{array}{l}\text { Dependant } \\
\text { Variables }\end{array}$ & Predictors & $\chi^{2}$ & Df & $P$ & $\beta \pm S E(P)$ \\
\hline \multirow{8}{*}{ Bite rate } & & & & & (intercept: $30.610 \pm 1.281$ ) \\
\hline & Plot enrichment & 1.354 & 1 & 0.245 & \\
\hline & Predator within $2 \mathrm{~km}$ & 7.080 & 1 & 0.008 & Yes: $-3.559 \pm 1.177$ \\
\hline & & & & & Medium: $1.860 \pm 1.321(0.161)$ \\
\hline & Grass height & 11.904 & 3 & 0.008 & Short: $6.252 \pm 2.430(\mathbf{0 . 0 1 1})$ \\
\hline & & & & & Short cut: $9.258 \pm 2.232(<0.001)$ \\
\hline & Plot enrichment $\times$ Predator within $2 \mathrm{~km}$ & 0.147 & 1 & 0.701 & \\
\hline & Predator within $2 \mathrm{~km} \times$ Grass height & 6.221 & 1 & 0.101 & \\
\hline \multirow{6}{*}{ Log (Step rate) } & & & & & (intercept: $0.548 \pm 0.084$ ) \\
\hline & Plot enrichment & 2.013 & 1 & 0.154 & \\
\hline & Predator within $2 \mathrm{~km}$ & 0.596 & 1 & 0.440 & \\
\hline & Grass height & 0.618 & 3 & 0.893 & \\
\hline & Plot enrichment $\times$ Predator within $2 \mathrm{~km}$ & 0.009 & 1 & 0.925 & \\
\hline & Predator within $2 \mathrm{~km} \times$ Grass height & 4.836 & 1 & 0.180 & \\
\hline \multirow{6}{*}{$\begin{array}{l}\text { Log (Bites per } \\
\text { feeding station) }\end{array}$} & & & & & (intercept: $0.929 \pm 0.110$ ) \\
\hline & Plot enrichment & 0.574 & 1 & 0.449 & \\
\hline & Predator within $2 \mathrm{~km}$ & 0.181 & 1 & 0.671 & \\
\hline & Grass height & 1.601 & 3 & 0.659 & \\
\hline & Plot enrichment $\times$ Predator within $2 \mathrm{~km}$ & 0.013 & 1 & 0.910 & \\
\hline & Predator within $2 \mathrm{~km} \times$ Grass height & 4.797 & 1 & 0.187 & \\
\hline
\end{tabular}


Table 3. Effect of the presence of a GPS-collared predator within the $2 \mathrm{~km}$ surroundings when comparing focals on days when collared predators had been in the vicinity during the previous 24 hours with observations on days before their arrival on the log-transformed total time spent in vigilance (Total vigilance) and exclusive (high-cost) vigilance of impalas considering the effects of grass height (High, medium, short, short cut). We contrasted 4 classes (days before predators had been in the vicinity, lion only, wild dog only, lion with hyaena) with in italics, classes that were considered as references. Year, Season and Predator event ID were included as nested random factors. $\beta \pm \mathrm{SE}$ are indicated for significant variables.

\begin{tabular}{llllll}
\hline Dependent variables & Predictors & $\chi^{2}$ & Df & $P$ & $\beta \pm S E(P)$ \\
\hline \multirow{2}{*}{$\begin{array}{l}\text { Log total vigilance } \\
\end{array}$} & Predator within 2 km & 7.192 & 2 & $\mathbf{0 . 0 2 7}$ & See table 4 for multiple comparison \\
& Grass height & 5.245 & 3 & 0.157 & \\
\hline \multirow{2}{*}{$\begin{array}{l}\text { Log exclusive } \\
\text { vigilance }\end{array}$} & Predator within 2 km & 7.180 & 2 & $\mathbf{0 . 0 2 8}$ & See table 4 for multiple comparison \\
& Grass height & 1.605 & 3 & 0.658 & \\
\hline
\end{tabular}


Table 4. Post-hoc Tukey test on the effect of the presence of GPS-collared predators within $2 \mathrm{~km}$, contrasting 4 classes (days before the predators' arrival, lion only, wild dog only vs lion with hyaena) on the log-transformed total time spent in vigilance (Log Total Vigilance) and high-cost vigilance (Log Exclusive Vigilance). The data on hyaenas were too sparse to allow the effect of this species to be analysed alone.

\begin{tabular}{lrrrrrrr}
\hline \multirow{2}{*}{ Contrast } & \multicolumn{3}{l}{ Log(Total vigilance) } & \multicolumn{4}{l}{ Log(Exclusive vigilance) } \\
& $\mathrm{B}$ & $\mathrm{SE}$ & $\mathrm{P}$ & $\beta$ & $\mathrm{SE}$ & $\mathrm{P}$ \\
\hline Lion only - Days before & 0.131 & 0.071 & 0.070 & 0.377 & 0.253 & 0.138 \\
Wild dog only - Days before & 0.332 & 0.118 & $\mathbf{0 . 0 0 5}$ & 0.960 & 0.558 & $\mathbf{0 . 0 4 6}$ \\
Lion with hyaena - Days before & 0.476 & 0.148 & $\mathbf{0 . 0 0 2}$ & 1.023 & 0.317 & $\mathbf{0 . 0 0 1}$ \\
Wild dog only - Lion only & 0.220 & 0.114 & $\mathbf{0 . 0 4 1}$ & 0.261 & 0.245 & 0.288 \\
Lion with hyaena - Lion only & 0.344 & 0.145 & $\mathbf{0 . 0 1 8}$ & 0.908 & 0.311 & $\mathbf{0 . 0 0 4}$ \\
Lion with hyaena - Wild dog only & 0.144 & 0.172 & 0.404 & 0.647 & 0.370 & 0.082 \\
\hline
\end{tabular}




\section{Figure legends}

FIGURE 1 Expected variations of functional parameters of feeding behaviour in impala with patch quality (as indicated by the interaction between grass height and enriched), and predation risk. BR is bite rate, i.e. the number of bites per min, $S R$ is step rate, i.e. the number of steps per min, and $B / S$ is the number of bites per feeding station i.e. the ratio between the number of bites and steps. The arrows and grey lines indicate how an individual would be expected to adjust its functional parameters of feeding behaviour to an increase of predation risk (see Introduction for more details on expected mechanisms): (a) when predation risk is low, the number of bites per feeding station increases with patch quality; (b) when perceived predation risk increases, the time spent grazing decreases so does the number of bites per feeding station at a feeding station (Pattern 1.1) or (c) increases the acceptability of bites (and thus the number of bites per feeding station) at the feeding station (Pattern 1.2); (d) when predators are present leading to an increase of high-cost vigilance altering the number of bites per feeding station (Pattern 2).

FIGURE 2 Experimental design for manipulating the quality of feeding patches for free-ranging impalas in Hwange National Park, Zimbabwe. (a) and (b) the location of our study area, (c) an overview of the experimental design, (d) plot features and (e) an aerial photograph of one plot.

FIGURE 3 Effect of patch quality on foraging parameters of impala over the 2-year experiment: (a) the effect of grass height on bite rate, (b) the effect of plot enrichment and (c) the effect of grass height on the log-transformed step rate, (d) the effect of plot enrichment and (e) the effect of grass height on the log-transformed bites per step. Lines of box plots indicate the lower quartile (25\%), median in bold (50\%) and upper quartile (75\%). The black dot within the box indicates mean value. 
Whiskers indicate the minimum and maximum values excluding outliers (open dots). Outliers are values less than 1.5 times the lower quartile and more than 1.5 times the upper quartile.

FIGURE 4 Trade-off between investment in vigilance and food acquisition in impalas. This trade-off is represented by the decrease of bite rate with the log-transformed time spent in vigilance in impala over the 2-year experiment.

FIGURE 5 Effect of the presence of GPS collared predators on investment in vigilance in impalas. The analysis contrasted focals sampled during days with predators and the ones sampled the day before the predators' arrival (called days before) distinguishing when lion, wild dog and both lion and hyaena were present within a $2 \mathrm{~km}$ radius around the focal impala. See title of Fig. 3 for details on features of box plots. The data on hyaenas were too sparse to allow the effect of this species to be analysed alone. 
Figure 1

(a) Low predation risk

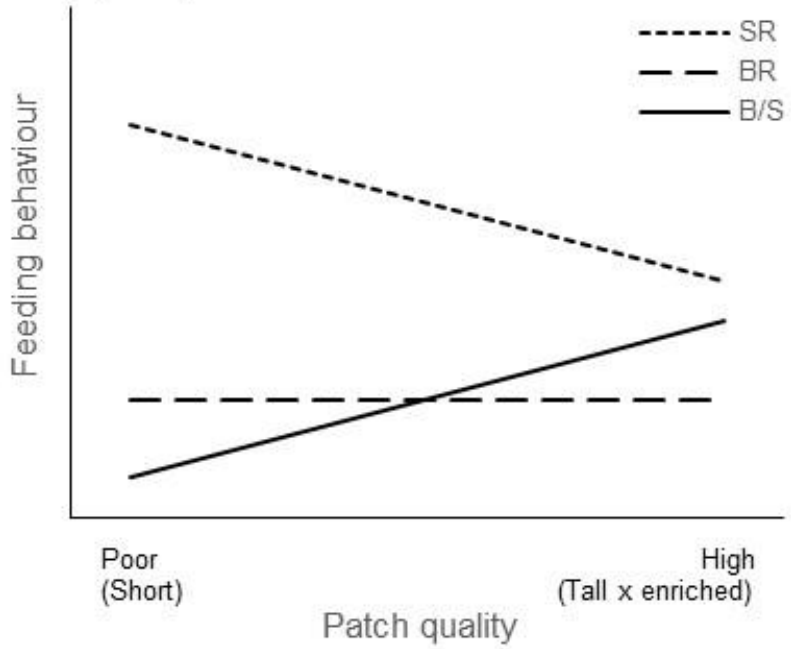

(c) When perceived predation risk increases

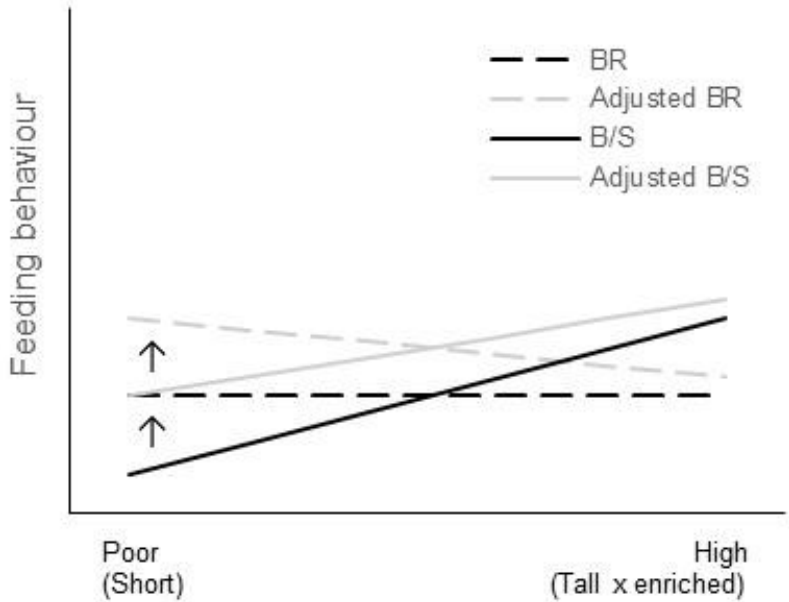

Pach quality (b) When perceived predation risk increases

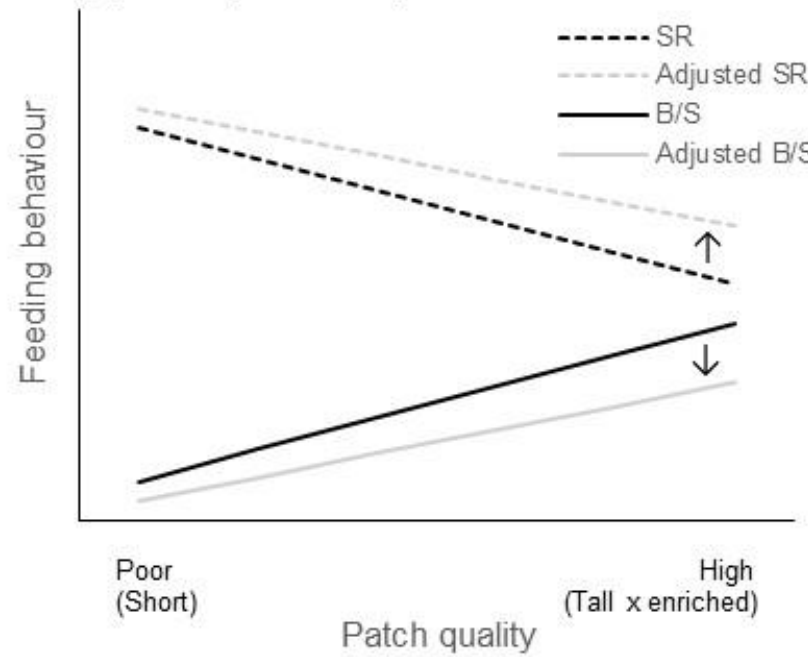

(d) When predators are present

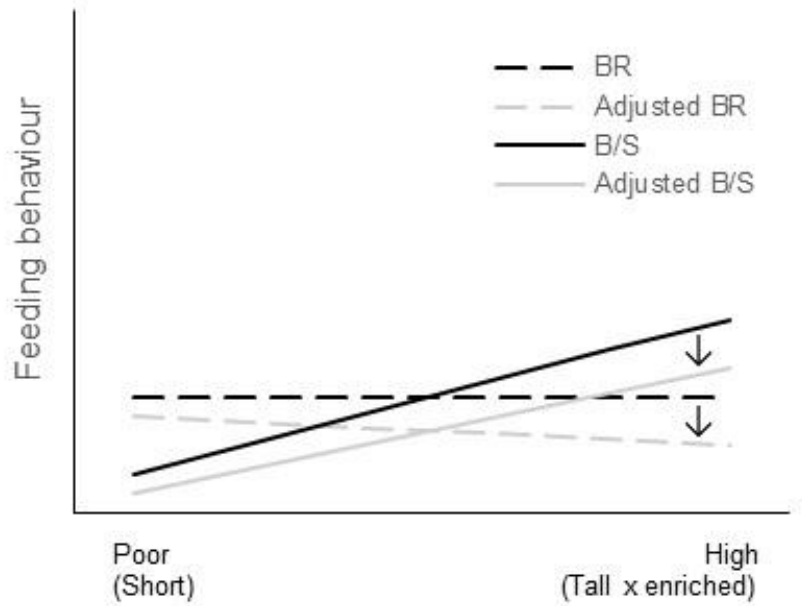

Patch quality 
Figure 2

(a)

(c)

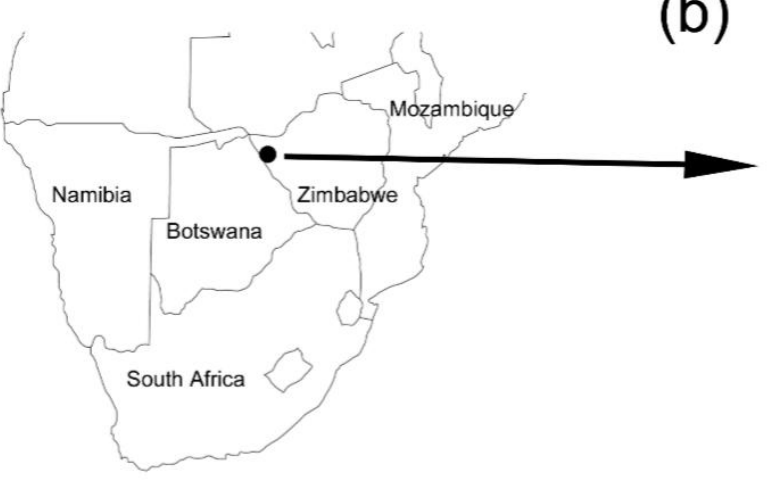

(b)


(d)

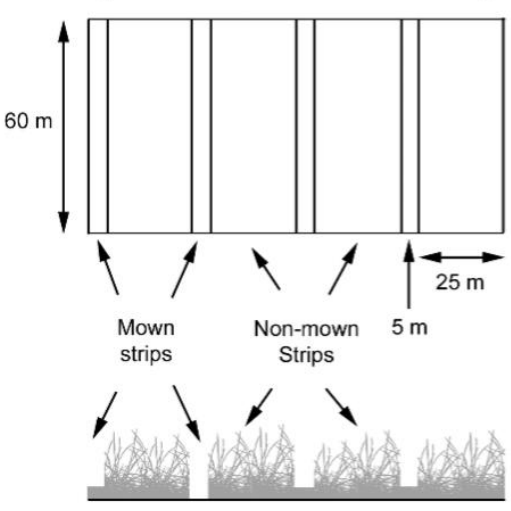

Top view

View Profile

(e)

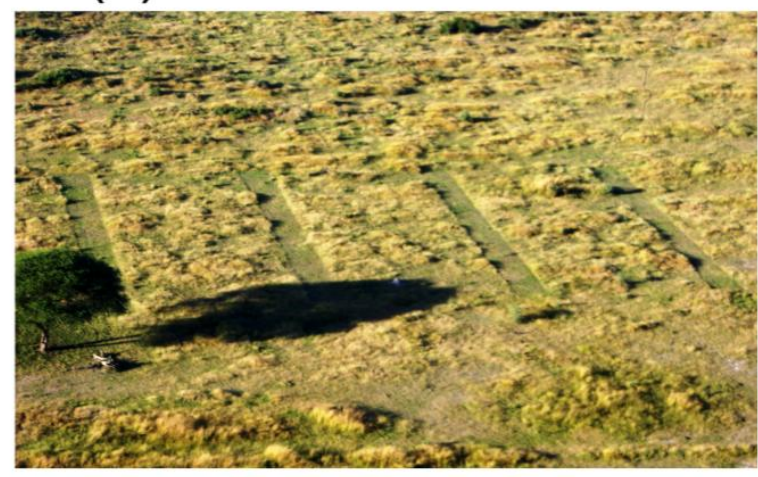

Aerial photograph of plot G

Control or enriched plot 
Figure 3

a)

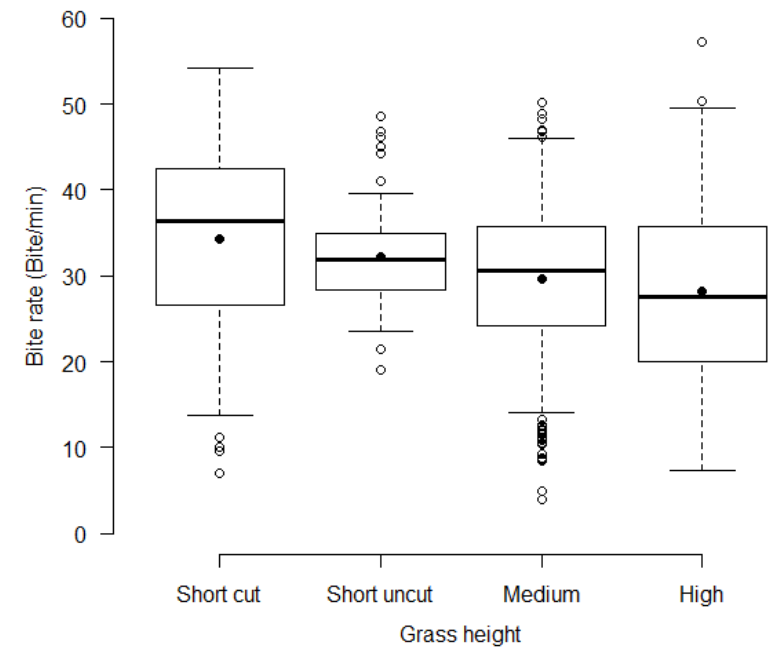

b)

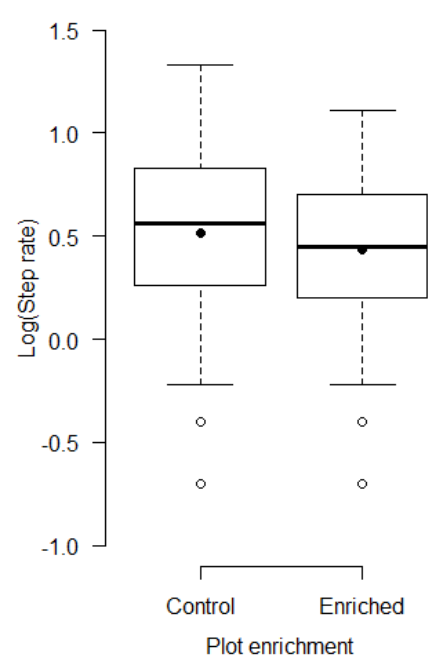

c)

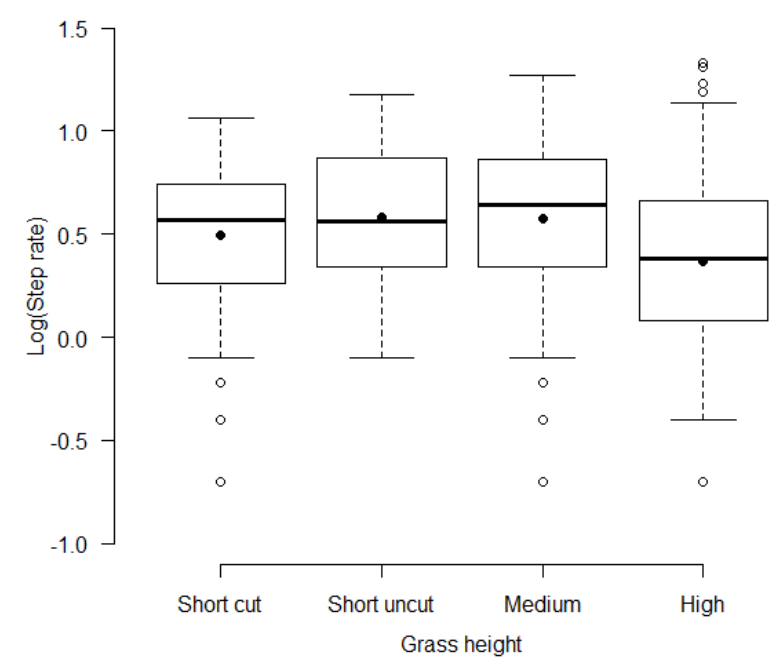

d)

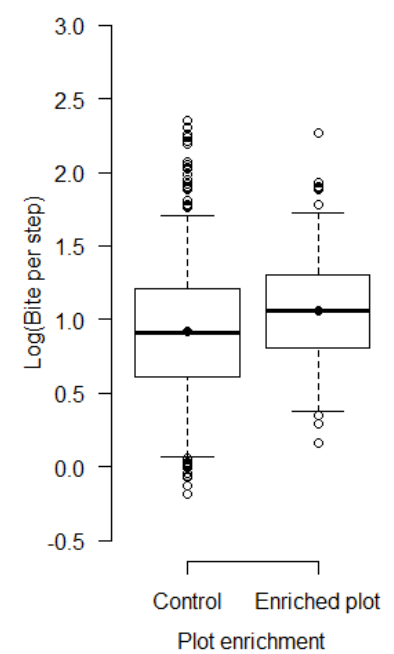

e)

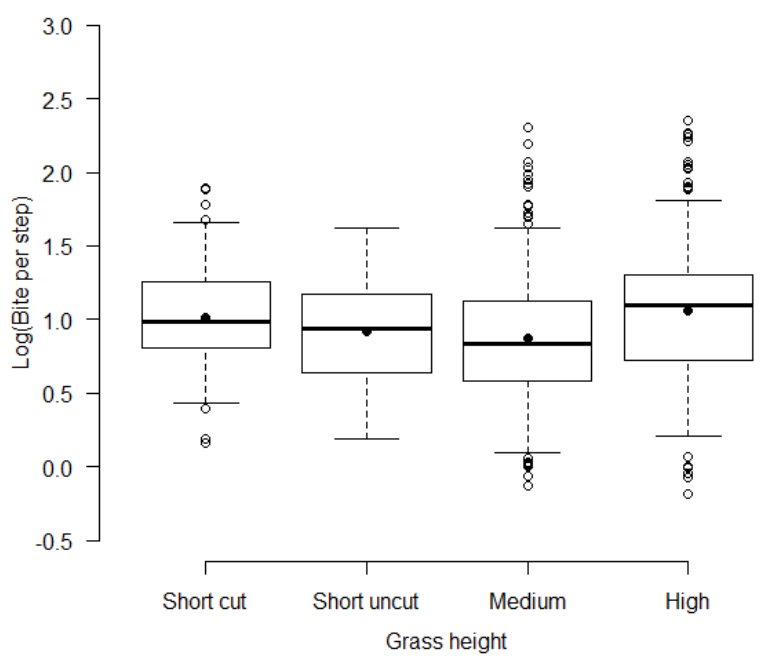


Figure 4

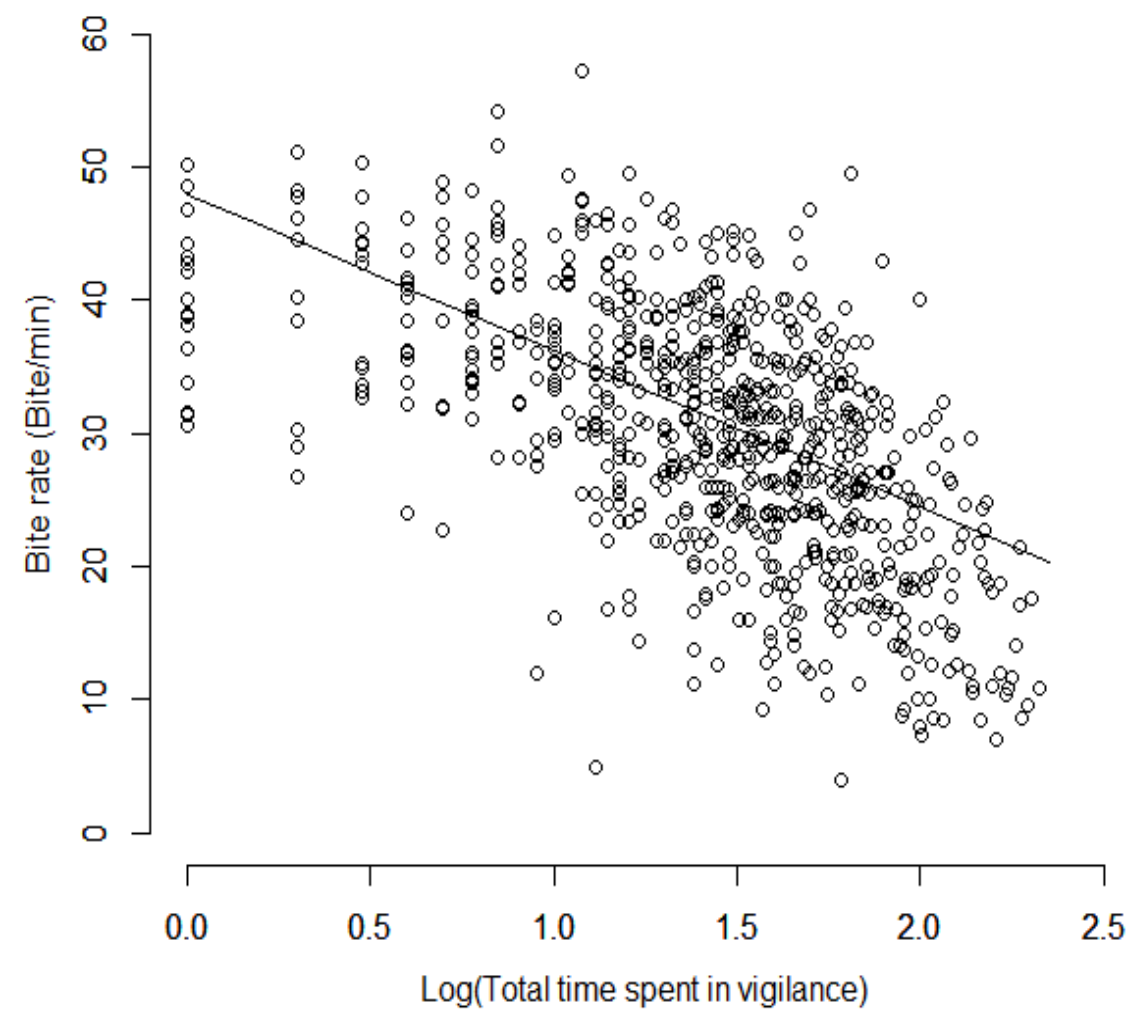


Figure 5






\section{Appendix 1}

We tested for differences of biomass and proportions of green tissues and bare soil between enriched and control plots, cut and uncut strips controlling for season and year.

In the uncut strips, biomass was on average higher in enriched plots compared to control plots in 2009: February $\left(\beta_{\text {enriched }} \pm \mathrm{SE}=0.070 \pm 0.030, \mathrm{P}=0.019\right)$, March $\left(\beta_{\text {enriched }} \pm \mathrm{SE}=0.059 \pm 0.039, \mathrm{P}=\right.$ $0.127)$ and May $\left(\beta_{\text {enriched }} \pm \mathrm{SE}=0.079 \pm 0.042, \mathrm{P}=0.060\right) 2009$; March $\left(\beta_{\text {enriched }} \pm \mathrm{SE}=0.140 \pm 0.033\right.$, $\mathrm{P}<0.001)$ and July $\left(\beta_{\text {enriched }} \pm \mathrm{SE}=0.098 \pm 0.057, \mathrm{P}=0.048\right) 2010$ (Fig 3). In the cut strips, biomass did not differ between enriched and control plots in February $(\mathrm{P}=0.156)$, March $(\mathrm{P}=0.674)$, May $(\mathrm{P}$ $=0.940) 2009$ and in March $(\mathrm{P}=0.237)$ and July $(\mathrm{P}=0.280) 2010$ (Fig S1).
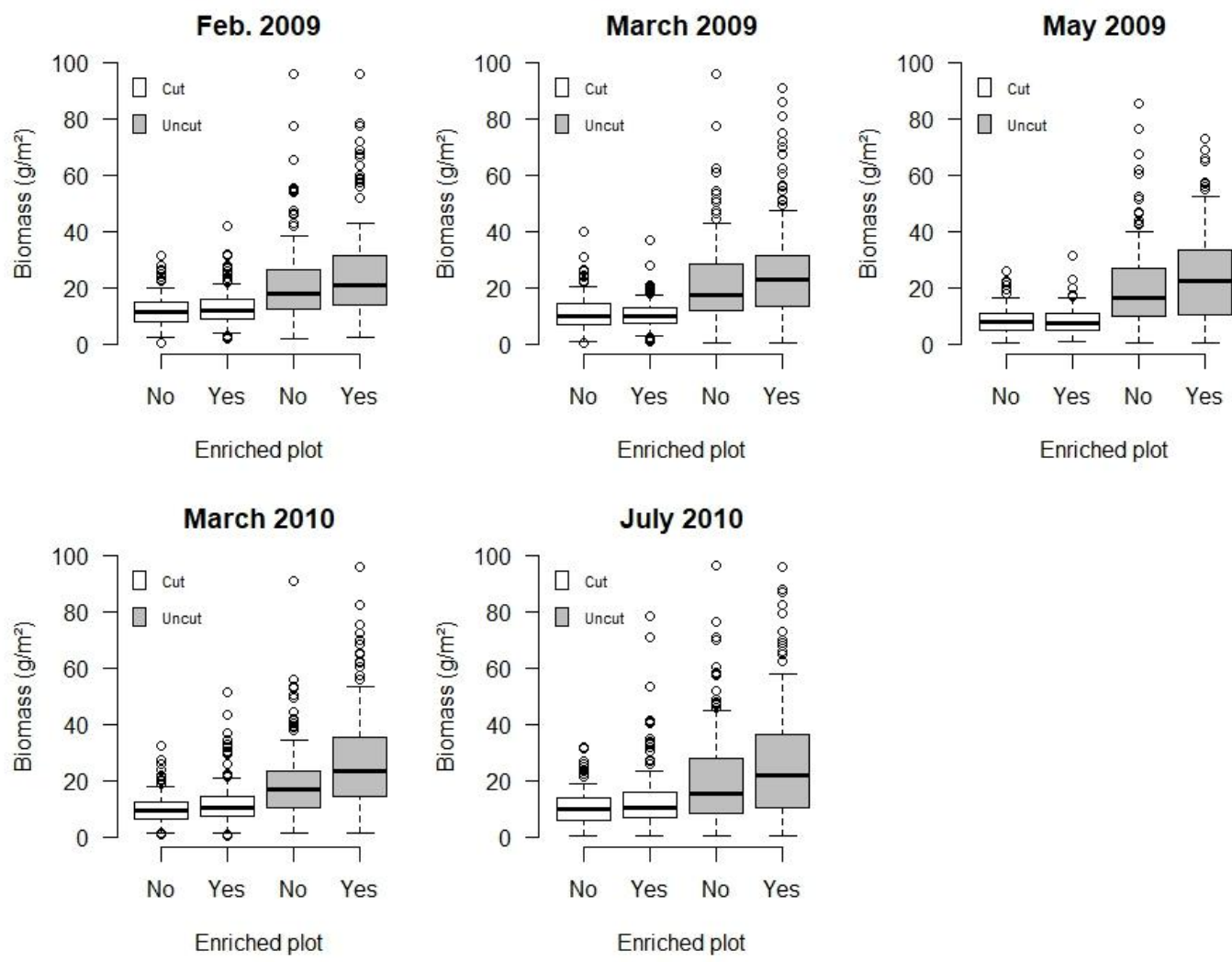

Fig. S1. Variation of grass biomass between enriched and control plots, cut and uncut strips over the 2 years of the experiment.

In the cut and uncut strips in 2009, the proportion of green tissues was higher in enriched plots compared to control plots in April $\left(\beta_{\text {enriched in cut }} \pm \mathrm{SE}=0.078 \pm 0.036, \mathrm{P}=0.032, \beta_{\text {enriched in uncut }} \pm \mathrm{SE}=\right.$ $0.131 \pm 0.041 ; \mathrm{P}=0.002)$ as well as in July $2010\left(\beta_{\text {enriched in cut }} \pm \mathrm{SE}=0.032 \pm 0.014, \mathrm{P}=0.019\right)$ while we did not detect any difference in green tissues among the uncut strips $(\mathrm{P}=0.456)$ (Fig S2). The 
proportion of green tissues was higher in April 2009 compared to July $2010\left(\beta_{\text {April }} \pm \mathrm{SE}=0.188 \pm\right.$ $0.011, \mathrm{P}<0.001)$ and in cut compared to uncut strips $\left(\beta_{\mathrm{Cut}} \pm \mathrm{SE}=0.025 \pm 0.009, \mathrm{P}=0.009\right)(\mathrm{Fig} \mathrm{S} 2)$.

In cut and uncut strips, the proportion of bare soil was less in enriched plots compared to control plots in April $2009\left(\beta_{\text {enriched in cut }} \pm \mathrm{SE}=-0.116 \pm 0.039, \mathrm{P}=0.003, \beta_{\text {enriched in uncut }} \pm \mathrm{SE}=-0.123 \pm\right.$ $0.048, \mathrm{P}=0.012)$ as well as in July $2010\left(\beta_{\text {enriched in cut }} \pm \mathrm{SE}=-0.178 \pm 0.028, \mathrm{P}<0.001 ; \beta_{\text {enriched in uncut }} \pm\right.$ $\mathrm{SE}=-0.187 \pm 0.028, \mathrm{P}<0.001)($ Fig S2). We did not detect any difference in the proportion of bare soil between April 2009 and July $2010(\mathrm{P}=0.793)$ while the proportion of bare soil was higher in the cut compared to uncut strips $(\beta \pm \mathrm{SE}=0.069 \pm 0.018, \mathrm{P}<0.001)($ Fig $\mathrm{S} 2)$.


Fig. S2. Variation of the proportion of green tissues and bare soil between enriched and control plots, cut and uncut strips over the 2 years of the experiment. 


\section{Appendix 2}

Lions are known to live in a fusion-fission society but the frequency of pride fission increases with increase in pride size (Mbizah et al. 2019. Applying the resource dispersion hypothesis to a fission-fusion society: a case study of the African lion (Panthera leo) Ecology and Evolution 9: 9111-9119). In the Main Camp area, where the study site is located, prides are rather small and composed of up to 4 female adults and previous work has revealed that lionesses from the same pride stay together most of the time, with females from a pride sighted together in $89.2 \%$ of sightings (Valeix et al. 2009. article in Ecology cited in the manuscript). Therefore, for lions, we can be rather confident that the movements of the collared individuals are quite representative of the movements of almost all lions around the study site (only dispersing individuals were missed).

Regarding wild dogs, members from a pack always stay together except during the denning period when some individuals become helpers at the den. So overall, the individuals that have been GPS collared per pack were representative of the movements of all individuals in their pack around the study site.

Regarding spotted hyaenas, because clans are characterized by a very high level of fissionfusion, we have to acknowledge that the movements of the collared individuals cannot be considered representative of the members of the monitored clans. Hence, the results about hyaenas must be interpreted with caution, as it is very likely that the movements of uncollared individuals were missed. However, we believe that the effect of undetected hyaenas should mainly reduce our capacity to detect differences. 


\section{Appendix 3}

Post-hoc Tukey tests on the effect of grass height on bite rate (bites per minute), step rate (steps per minute) and number of bites per step (Log-transformed) over the 2-year period ${ }^{\text {(a) }}$ and when comparing focals when equipped predators were present with the days before their arrival $^{(b)}$.

\begin{tabular}{|c|c|c|c|c|c|c|c|c|c|c|c|c|}
\hline \multirow{2}{*}{ Contrast } & \multicolumn{3}{|c|}{ Bite rate $^{a}$} & \multicolumn{3}{|c|}{ Bite rate $^{b}$} & \multicolumn{3}{|c|}{ Log(Step rate) ${ }^{a}$} & \multicolumn{3}{|c|}{ Log(Bite per step $)^{a}$} \\
\hline & $\beta$ & SE & $P$ & $\beta$ & SE & $\mathrm{P}$ & $\beta$ & SE & $P$ & B & SE & $P$ \\
\hline High - Medium & 1.461 & 0.789 & 0.065 & 1.389 & 1.340 & 0.301 & 0.104 & 0.032 & 0.001 & -0.117 & 0.037 & 0.002 \\
\hline High - Short uncut & 4.060 & 1.409 & 0.005 & 5.507 & 2.469 & 0.026 & 0.195 & 0.054 & $<0.001$ & -0.116 & 0.062 & 0.060 \\
\hline High - Short cut & 3.073 & 1.327 & 0.021 & 9.471 & 2.278 & $<0.001$ & 0.186 & 0.053 & $<0.001$ & -0.147 & 0.058 & 0.013 \\
\hline Medium - Short uncut & 2.606 & 1.363 & 0.056 & 4.117 & 2.318 & 0.077 & 0.091 & 0.053 & 0.085 & 0.001 & 0.060 & 0.992 \\
\hline Medium - Short cut & 4.642 & 1.037 & $<0.001$ & 8.082 & 2.113 & $<0.001$ & 0.082 & 0.054 & 0.126 & -0.029 & 0.060 & 0.615 \\
\hline Short uncut- Short cut & 2.036 & 1.555 & 0.191 & 3.964 & 2.961 & 0.182 & -0.009 & 0.071 & 0.899 & -0.030 & 0.079 & 0.703 \\
\hline
\end{tabular}




\section{Appendix 4}

Fig. S3. Diagnostic plots on the structure of residuals from the linear mixed-effects model investigating the plot enrichment, predator within $2 \mathrm{~km}$, grass height and their two-was interactions and including year, season and plot ID (a-c) or predator event ID (d-f) as three nested random factors on bite rate in the impalas over the 2-year experiment (a-c) and contrasting focals sampled during days with predators and focals on the days before predators' arrivals (d-f). An autocorrelation function of order 1 ("corAR1") was also considered in models to control for the sequential structure of the data set (see Methods). The residuals against fitted values in (a) and (d) show that the variance remains approximately constant as the fitted values increased. (b) and (e) show that the distribution of residuals was consistent with normality. (c) and (f) show the autocorrelation function (ACF) estimated on residuals. The horizontal dotted lines provide an approximate $95 \%$ confidence interval for the autocorrelation estimate at each lag and reveal that sequential correlation was controlled.

a)

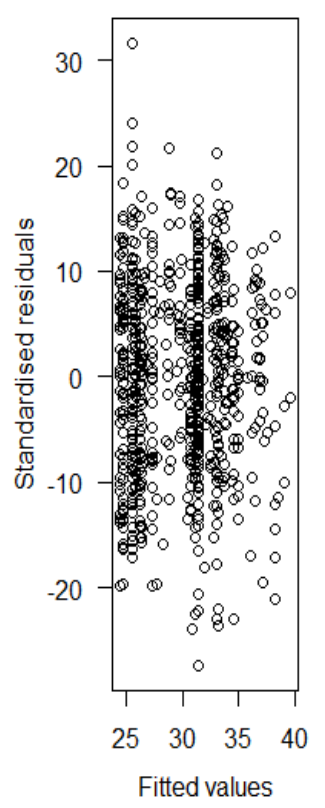

d)

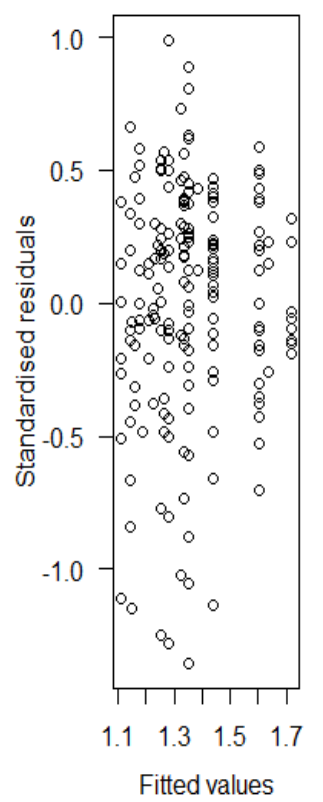

b)

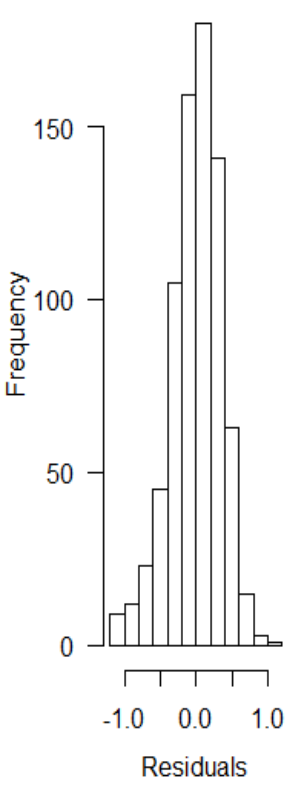

e)

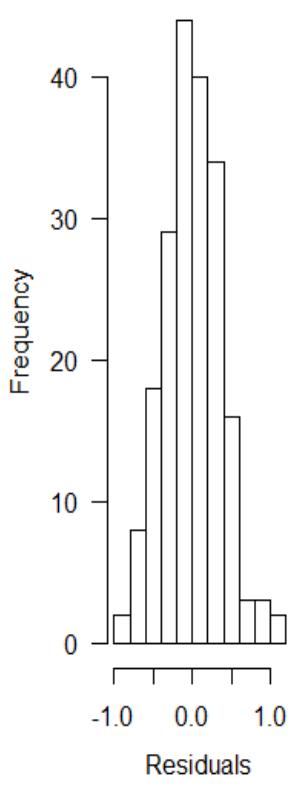

c)

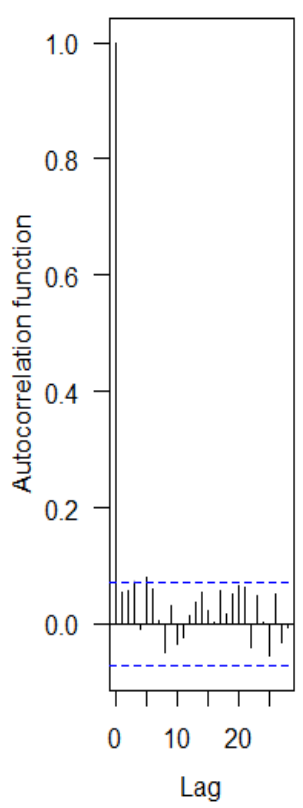

f)

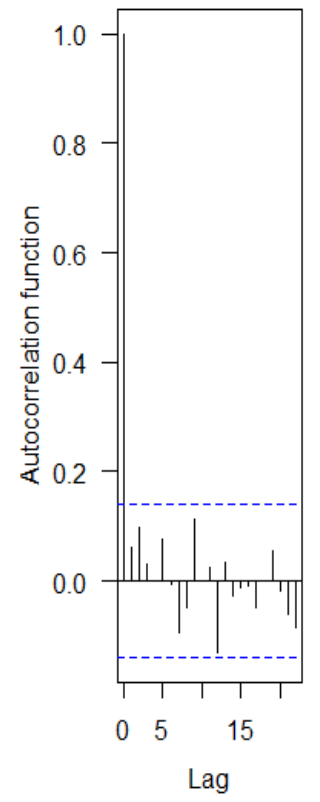


